Review

\title{
Nitrification Progress of Nitrogen-Rich Heterocyclic Energetic Compounds: A Review
}

\author{
Yiming Luo ${ }^{1,2,+}$, Wanwan Zheng ${ }^{3,+}$, Xuanjun Wang ${ }^{1, *}$ and Fei Shen ${ }^{1,2}$ \\ 1 High-Tech Institute of Xi'an, Xi'an 710025, China; iamrlym@126.com (Y.L.); shenf02@163.com (F.S.) \\ 2 Xi'an Modern Chemistry Research Institute, Xi'an 710065, China \\ 3 School of Chemical Engineering, Northwest University, Xi'an 710069, China; zhengwan2020@163.com \\ * Correspondence: wangxj503@sina.com \\ + These authors contributed equally to this work.
}

Citation: Luo, Y.; Zheng, W.; Wang, X.; Shen, F. Nitrification Progress of Nitrogen-Rich Heterocyclic Energetic Compounds: A Review. Molecules 2022, 27, 1465. https://doi.org/ $10.3390 /$ molecules 27051465

Academic Editor: Fawaz Aldabbagh

Received: 16 January 2022

Accepted: 18 February 2022

Published: 22 February 2022

Publisher's Note: MDPI stays neutral with regard to jurisdictional claims in published maps and institutional affiliations.

Copyright: (c) 2022 by the authors. Licensee MDPI, Basel, Switzerland. This article is an open access article distributed under the terms and conditions of the Creative Commons Attribution (CC BY) license (https:/ / creativecommons.org/licenses/by/ $4.0 /)$.

\begin{abstract}
As a momentous energetic group, a nitro group widely exists in high-energy-density materials (HEDMs), such as trinitrotoluene (TNT), 1,3,5-triamino-2,4,6-trinitrobenzene (TATB), cyclo1,3,5-trimethylene-2,4,6-trinitramine (RDX), etc. The nitro group has a significant effect on improving the oxygen balance and detonation performances of energetic materials (EMs). Moreover, the nitro group is a strong electron-withdrawing group, and it can increase the acidity of the acidic hydrogencontaining nitrogen-rich energetic compounds to facilitate the construction of energetic ionic salts. Thus, it is possible to design nitro-nitrogen-rich energetic compounds with adjustable properties. In this paper, the nitration methods of azoles, including imidazole, pyrazole, triazole, tetrazole, and oxadiazole, as well as azines, including pyrazine, pyridazine, triazine, and tetrazine, have been concluded. Furthermore, the prospect of the future development of nitrogen-rich heterocyclic energetic compounds has been stated, so as to provide references for researchers who are engaged in the synthesis of EMs.
\end{abstract}

Keywords: nitro group; nitration; nitrogen rich heterocycle; energetic materials

\section{Introduction}

Nitrogen-rich compounds have attracted widespread attention in energetic materials (EMs) because of their advantages of outstanding density, excellent positive enthalpy of formation, remarkable detonation performance, and high thermal stability [1-3]. They can be used in explosives, propellants, gas generators, and smokeless pyrotechnic fuels [4,5]. In order to meet the increasing performance requirements, new nitrogen-rich EMs are being developed with upgradable density, better detonation performance, lower impact and friction sensitivity, and higher thermal stability.

One of the most popular strategies for the design of promising new EMs is the incorporation of both fuel and oxidizer moieties into one molecule. [6,7] The nitro group is a pivotal explosive group, which exists in trinitrotoluene (TNT), 1,3,5-triamino-2,4,6-trinitrobenzene (TATB), cyclo-1,3,5-trimethylene-2,4,6-trinitramine (RDX), cyclo-1,3,5-7-tetramethylene-2,4,6,8tetranitr-amine (HMX), and hexanitrohexaazaisowurtzitane (CL-20), etc. Nitro groups in the molecular structure can heighten the oxygen balance, increase the density, and significantly enhance the detonation performance of EMs [8,9]. Moreover, the nitro group is a strong electron-withdrawing group, and it can increase the acidity of hydrogen-containing nitrogenrich energetic compounds and is conducive to the construction of energetic ionic salts [10]. Therefore, this paper reviews the nitrification methods for nitrogen-rich heterocyclic energetic compounds so as to give some suggestions for this special reaction.

The main skeletons of nitrogen-rich heterocyclic energetic compounds are azole rings (imidazole, pyrazole, triazole, tetrazole, oxadiazole) and azine rings (pyrazine, pyridazine, triazine, tetrazine) [11,12]. Different nitration systems can be used to nitrate specific compounds on the basis of the structural characteristics of compounds [13]. According 
to the diversity of the nitration positions on these frameworks, this paper classifies the nitration of $\mathrm{H}$ on heterocyclic $\mathrm{C}$, the nitration of $-\mathrm{NH}_{2}$ on heterocyclic $\mathrm{C}$, the nitration of $\mathrm{H}$ on heterocyclic $\mathrm{N}$, and the nitration of $-\mathrm{NH}_{2}$ on heterocyclic $\mathrm{N}$.

\section{Nitrification of Azoles Nitrogen-Rich Heterocyclic Energetic Compounds}

\subsection{Imidazoles}

\subsubsection{Nitrification of $\mathrm{H}$ on Imidazole Ring $\mathrm{C}$}

$4,4^{\prime}, 5,5^{\prime}$-tetranitro-2, $2^{\prime}$-benzimidazole (TNBI) is an important precursor for the synthesis of EMs. It has been synthesized by two nitrification systems.

\section{(1) $\mathrm{NaNO}_{3} / \mathrm{H}_{2} \mathrm{SO}_{4}$ system}

Klapötke et al. [14] synthesized 2,2'-biimidazole (BI) from glyoxal and sodium bisulfite by cyclization, suspended $\mathrm{NaNO}_{3}$ and urea in concentrated $\mathrm{H}_{2} \mathrm{SO}_{4}\left(96-98 \%\right.$ ) at $0{ }^{\circ} \mathrm{C}$, and added $\mathrm{BI}$ in small batches. The suspension was stirred for $1 \mathrm{~h}$ at ambient temperature, and then heated to $85-90{ }^{\circ} \mathrm{C}$ for $16 \mathrm{~h}$. Thereafter, the suspension was poured onto crushed ice, filtered, and washed with ice water to obtain TNBI- $2 \mathrm{H}_{2} \mathrm{O}$, with a yield of $51 \%$. The synthesis route is shown in Scheme 1.

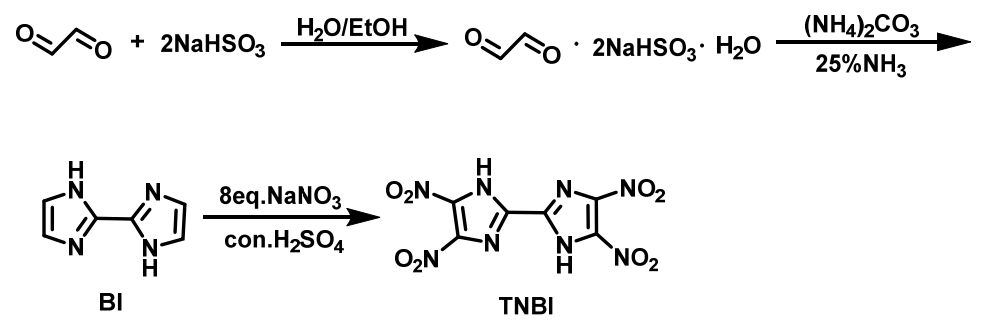

Scheme 1. Synthesis of $4,4^{\prime}, 5,5^{\prime}$-tetranitro-2, $2^{\prime}$-biimidazole [14].

\section{(2) $80 \% \mathrm{HNO}_{3} / \mathrm{H}_{2} \mathrm{SO}_{4}$ system}

Li et al. [15] synthesized $\mathrm{BI}$ using ammonium acetate $\left(\mathrm{CH}_{3} \mathrm{COONH}_{4}\right)$ and glyoxal as raw materials. Then, $\mathrm{BI}$ was added to $95-98 \%$ concentrated $\mathrm{H}_{2} \mathrm{SO}_{4}$ at $20-25^{\circ} \mathrm{C}$. After that, the mixed solution of $80 \% \mathrm{HNO}_{3}$ and $95-98 \% \mathrm{H}_{2} \mathrm{SO}_{4}$ was added dropwise as the mixture was heated to $45^{\circ} \mathrm{C}$. Four hours later, the reaction solution was poured onto crushed ice, filtered, washed with cold water, and dried to obtain TNBI. The synthesis route is shown in Scheme 2. The yield was $51.7 \%$. Compared with the traditional operation process [14], this strategy saves the reaction time and lowers the reaction temperature via a gentle and stable reaction process, thus, the danger of the reaction is reduced.

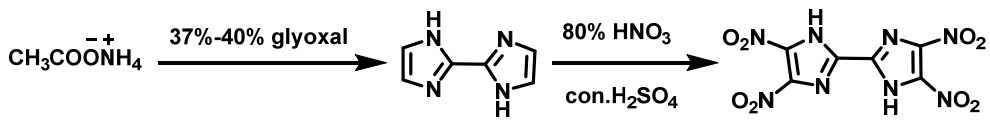

TNBI

Scheme 2. Synthesis of $4,4^{\prime}, 5,5^{\prime}$-tetranitro-2,2' -biimidazole [15].

\subsubsection{Nitration of $-\mathrm{NH}_{2}$ on Imidazole Ring $\mathrm{C} / \mathrm{N}$}

The $\mathrm{H}$ atom of $\mathrm{NH}_{2}$ can be nitrified to obtain different nitration products using the $\mathrm{HNO}_{3} / \mathrm{H}_{2} \mathrm{SO}_{4}$ system.

Thomas et al. [16] added 2-aminobenzimidazole (1) to the solution of $100 \% \mathrm{HNO}_{3}$ and concentrated $\mathrm{H}_{2} \mathrm{SO}_{4}(96-98 \%)$ while stirring at $0{ }^{\circ} \mathrm{C}$. After stirring for $48 \mathrm{~h}$ at $25^{\circ} \mathrm{C}$, the mixture was poured onto crushed ice, then filtered and washed with $20 \% \mathrm{HNO}_{3}$ and a small amount of water. The light yellow solid, 2-nitroammonium-5,6-dinitrobenz imidazole (2), was obtained with a yield of $41 \%$. The synthesis route is shown in Scheme 3. 


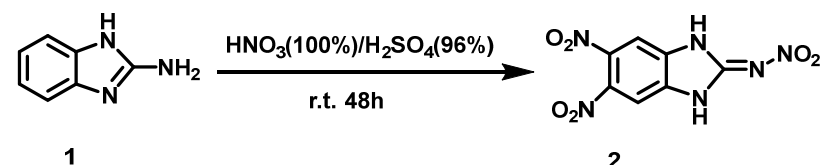

Scheme 3. Synthesis of 2-nitrimino-5,6-dinitrobenzimidazole [16].

Another example is nitration of $-\mathrm{NH}_{2}$ on imidazole ring N. Yin et al. [17] synthesized 4,4',5,5'-tetranitro- $1 H, 1^{\prime} H$-(2,2'-benzimidazole)-1,1'-diamine (4) from glyoxal and ammonium acetate by using condensation, nitration, and $\mathrm{N}$-amination reactions. Compound 4 was then slowly added to the $\mathrm{HNO}_{3} / \mathrm{H}_{2} \mathrm{SO}_{4}$ solution at $-10^{\circ} \mathrm{C}$ and stirred for $90 \mathrm{~min}$. The solution was subsequently poured onto crushed ice, stirred for about 10-15 min, filtered, and washed with ice-cooled water, ethanol, and ether to obtain $N, N^{\prime}$-dinitroamino- $4,4^{\prime}, 5,5^{\prime}$ tetranitro-bisimidazole (5). The synthesis route is shown in Scheme 4 . In order to prevent the N-N bond from being broken, the nitration reaction should be performed in a mixed acid at a temperature of -15 to $-10{ }^{\circ} \mathrm{C}$ because the $\mathrm{N}$-amino group is highly reactive. It has been found that the nitrification ability of $\mathrm{HNO}_{3} / \mathrm{H}_{2} \mathrm{SO}_{4}$ is stronger than that of $\mathrm{HNO}_{3}$, so $\mathrm{HNO}_{3} / \mathrm{H}_{2} \mathrm{SO}_{4}$ with an appropriate ratio is always selected for nitrating $\mathrm{NH}_{2}$ to $\mathrm{NHNO}_{2}$. The reaction condition is mostly mild and the operation is simple.

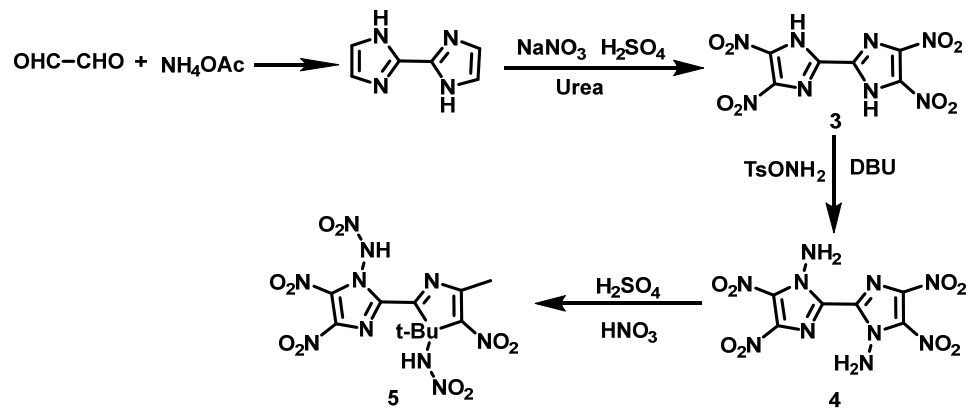

Scheme 4. Synthesis of $N, N^{\prime}$-dinitramino-4, $4^{\prime}, 5,5^{\prime}$-tetranitro-bisimidazole [17].

\subsubsection{Nitrification of $\mathrm{H}$ on Imidazole Ring $\mathrm{N}$}

\section{(1) $\mathrm{HNO}_{3} / \mathrm{Ac}_{2} \mathrm{O}$ system}

Chand et al. [18] synthesized compound 7 using benzimidazole as a raw material through iodination, nitration, substitution, and ring formation reactions (Scheme 5). Then, $100 \% \mathrm{HNO}_{3}$ was added dropwise to acetic anhydride $\left(\mathrm{Ac}_{2} \mathrm{O}\right)$ at $-5{ }^{\circ} \mathrm{C}$, and the resulting mixture was stirred for $0.5 \mathrm{~h}$. Compound 7 was then added to the reaction solution in portions and stirred for $2 \mathrm{~h}$. Afterwards, the reaction mixture was poured onto crushed ice. Compound 8 was obtained by filtration with a yield of $67 \%$. Compared with the nitrifying agent $\mathrm{HNO}_{3} / \mathrm{H}_{2} \mathrm{SO}_{4}$, the nitrifying ability of $\mathrm{HNO}_{3} / \mathrm{Ac}_{2} \mathrm{O}$ mixed solution is weaker, but $\mathrm{Ac}_{2} \mathrm{O}$ can effectively decrease the oxidizing property of $\mathrm{HNO}_{3}$ and avoid the formation of by-products of compound 8 .

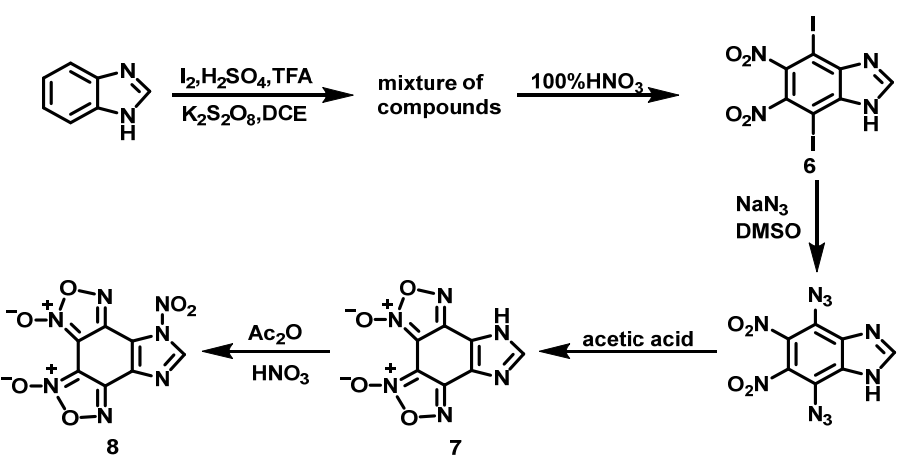

Scheme 5. Synthesis of 7-nitro-7H-imidazo[4' $, 5,5,6]$ benzo[1-4]bis([1,2,5]oxadiazole)-3,4-dioxide [18]. 


\subsection{Nitrification of Pyrazoles}

\subsubsection{Nitrification of H on Pyrazole Ring C}

(1) Bismuth nitrate/montmorillonite

P. Ravi et al. [19] added 1-methylpyrazole-2-oxide and montmorillonite (K-10) to a suspension of bismuth nitrate $\left(\mathrm{Bi}\left(\mathrm{NO}_{3}\right)_{3}\right)$ in tetrahydrofuran $(\mathrm{THF})$ and stirred for $2.5 \mathrm{~h}$. The solvent was then evaporated under reduced pressure using a vacuum pump for $5 \mathrm{~min}$. The mixture was repeatedly washed with dichloromethane $\left(\mathrm{CH}_{2} \mathrm{Cl}_{2}\right)$ and concentrated to give the crude K-10. The pure product was isolated by column chromatography with a yield of $98 \%$. The synthesis route is shown in Scheme 6. The ranking of nitration capacities of some nitrates is as follows: $\mathrm{Bi}\left(\mathrm{NO}_{3}\right)_{3}>\mathrm{AgNO}_{3}>\mathrm{KNO}_{3}>\mathrm{NaNO}_{3}>\mathrm{NH}_{4} \mathrm{NO}_{3}>\mathrm{Pb}\left(\mathrm{NO}_{3}\right)_{2}$ $>\mathrm{Ba}\left(\mathrm{NO}_{3}\right)_{2}$. In the reaction, $\mathrm{Bi}\left(\mathrm{NO}_{3}\right)_{3}$, which is impregnated on $\mathrm{K}-10$, has a fast nitration rate and high yield and is easy to separate from the product by filtration. The methyl group in the pyrazole ring contributes to the nitration process, and the nitration rate will increase with the number of methyl groups.

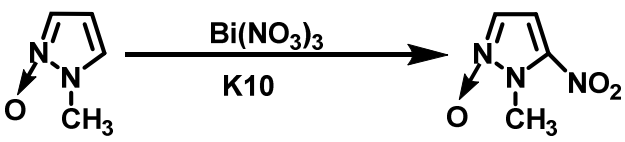

Scheme 6. Synthesis of 1-methyl-5-nitropyrazole- 2-oxide (K-10) [19].

\section{(2) $\mathrm{HNO}_{3} / \mathrm{H}_{2} \mathrm{SO}_{4}$ system}

The $\mathrm{HNO}_{3} / \mathrm{H}_{2} \mathrm{SO}_{4}$ system usually has a strong nitration effect. Fischer et al. [20] synthesized 4-chloropyrazole (9) using pyrazole as a raw material via chlorination reaction. Compound 9 was then dissolved in the concentrated $\mathrm{H}_{2} \mathrm{SO}_{4}$, and $100 \% \mathrm{HNO}_{3}$ was slowly added below $40{ }^{\circ} \mathrm{C}$. Then, the mixture was heated to $100{ }^{\circ} \mathrm{C}$ and stirred for $5 \mathrm{~h}$ under reflux. After cooling to room temperature, the final solution was poured onto crushed ice water and extracted with acetoacetic acid. The organic layers were washed with water, dried over magnesium sulfate, and dried under nitrogen to give 4-chloro-3,5-dinitro- $1 H$-pyrazole (10) in a yield of $86.7 \%$. The synthesis route is shown in Scheme 7 . The reaction is simple, no further purification is required, and the reaction yield is high.

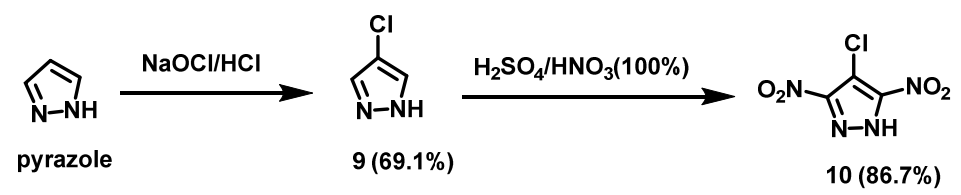

Scheme 7. Synthesis of 4-chloro-3,5-dinitropyrazole [20].

\section{(3) $\mathrm{HNO}_{3} / \mathrm{P}_{2} \mathrm{O}_{5}$ system}

Wang et al. [21] dissolved $\mathrm{P}_{2} \mathrm{O}_{5}$ in fuming $\mathrm{HNO}_{3}$ and then added (6-(3,5-dimethyl- $1 \mathrm{H}$ pyrazole-1-yl)-1,2,4-triazole[4,3-b]-1,2,4,5-tetrazine-3-amino (11) at $0{ }^{\circ} \mathrm{C}$. The reaction mixture was stirred for $10 \mathrm{~h}$ at room temperature. Then, the mixture was subsequently poured onto crushed ice, extracted with ethyl acetate, and purified by column chromatography to obtain N-(6-(3,5-dimethyl- 4-nitro-1H-pyrazole-1-yl)-1,2,4-triazolo[4,3-b]-1,2,4,5-tetrazin-3yl)nitramide (12) with a yield of 58\%. In this reaction, the $\mathrm{NH}_{2}$ in 1,2,4-triazol ring is also nitrated to $\mathrm{NHNO}_{2}$. The synthesis route is shown in Scheme 8. The nitrification system used in this reaction is $\mathrm{HNO}_{3} / \mathrm{P}_{2} \mathrm{O}_{5} \cdot \mathrm{P}_{2} \mathrm{O}_{5}$ is not only a dehydrating agent, but also a nitrification promoter. This nitration system is not only suitable for aromatics but also for amines. Even amines that are difficult to nitrate can get satisfactory results sometimes. 


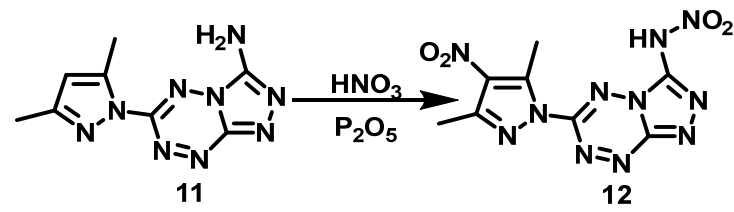

Scheme 8. Synthesis of N-(6-(3,5-dimethyl-4-nitro-1H-pyrazol-1-yl) -1,2,4-triazolo[4,3-b]-1,2,4,5tetrazine-3-yl)nitramide [21].

\subsubsection{Nitrification of -NH on Pyrazole Ring C}

(1) $100 \% \mathrm{HNO}_{3}$ system

$\mathrm{HNO}_{3}$ is a strong nitration agent, it can be used to nitrate $\mathrm{NH}_{2}$ to $\mathrm{NHNO}_{2}$. Yin et al. [22] synthesized 1,1'-(ethane-1,2-diyl)bis(3,5-dinitro-) $1 H$-pyrazole-4-amine) (14) using pyrazole as raw material through halogenation, nitration, neutralization, and alkylation reaction. Afterwards, compound 14 was added to $100 \% \mathrm{HNO}_{3}$ in portions below $10{ }^{\circ} \mathrm{C}$. The reaction was held for $10 \mathrm{~min}$ at $5{ }^{\circ} \mathrm{C}$, and $\mathrm{HNO}_{3}$ was removed by blowing in air. The residue was dried under vacuum to give $N, N^{\prime}$-[1, $1^{\prime}$-(ethane-1,2-diyl)bis(3,5-dinitro- $1 H^{-}$ pyrazole-4,1-diyl)]dinitramide (15). The synthesis route is shown in Scheme 9. This process uses $100 \% \mathrm{HNO}_{3}$ as the nitration system. For the nitration of different azole rings, different concentrations of $\mathrm{HNO}_{3}$ are required.

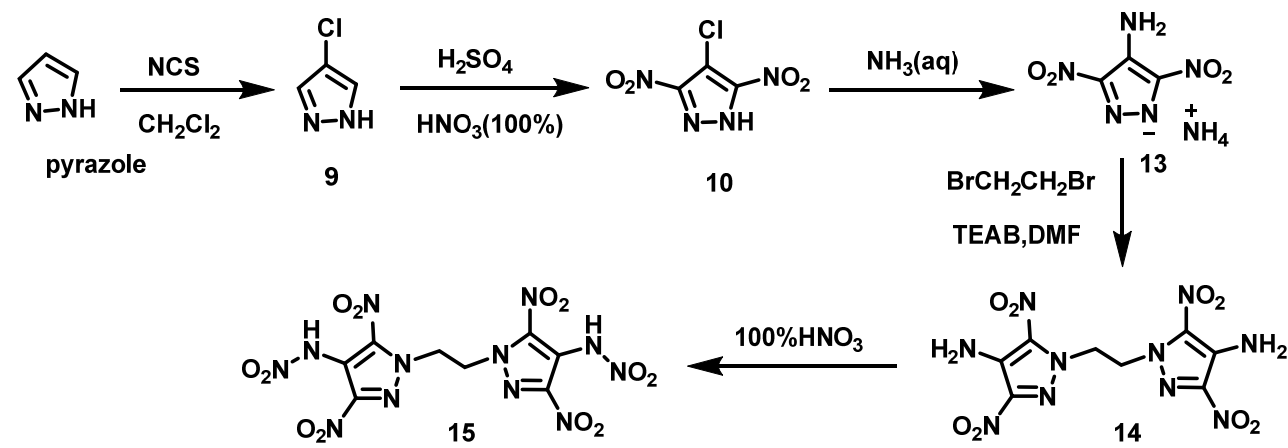

Scheme 9. Synthesis of $N, N^{\prime}$-[1,1'-(ethane-1,2-diyl)bis(3,5-dinitro-1H-pyrazole-4,1-diyl)]dinitramide [22].

(2) $70 \% \mathrm{HNO}_{3} / \mathrm{H}_{2} \mathrm{SO}_{4}$ system

Zhang et al. [23] added 4-amino-3,5-dinitropyrazole (16) to a mixture of $\mathrm{HNO}_{3}(70 \%)$ and concentrated $\mathrm{H}_{2} \mathrm{SO}_{4}$ in a volume ratio of $1: 1$ at $0{ }^{\circ} \mathrm{C}$. The mixture was stirred for $2 \mathrm{~h}$ and then slowly warmed to room temperature. After stirring for another $4 \mathrm{~h}$, the reaction mixture was poured into ice water and extracted with ether to obtain 4-nitroamino-3,5dinitropyrazole (17). The synthesis route is shown in Scheme 10.

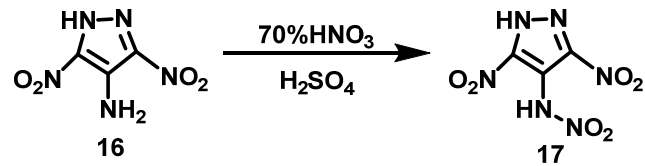

Scheme 10. Synthesis of 4-nitramino-3,5-dinitropyrazole [23].

\section{(3) $\mathrm{HNO}_{3} / \mathrm{Ac}_{2} \mathrm{O}$ system}

He et al. [23] synthesized 4-methylamino-3,5-dinitropyrazole (18) using 4-chloro-3,5dinitro pyrazole (10) as a raw material through nucleophilic substitution reaction. Firstly, $100 \% \mathrm{HNO}_{3}$ was slowly added to a cooled solution of compound 18 in acetic acid, after which $\mathrm{Ac}_{2} \mathrm{O}$ was added, and the mixture was stirred for $1.5 \mathrm{~h}$ at room temperature. 4 - $(\mathrm{N}$ methylnitramino)-3,5-dinitropyrazole (19) was finally obtained by removing excess acid under vacuum with a yield of $95 \%$. The synthesis route is shown in Scheme 11 . This reaction uses $\mathrm{HNO}_{3} / \mathrm{Ac}_{2} \mathrm{O}$ as a nitration system, which is simple to operate, has no by-products, and the yield is as high as $95 \%$. 


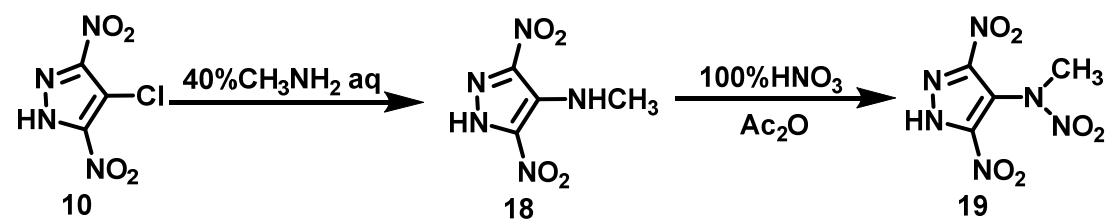

Scheme 11. Synthesis of 4-(N-methylnitramino)-3,5-dinitropyrazole [24].

\subsubsection{Nitrification of $\mathrm{H}$ on Pyrazole Ring $\mathrm{N}$}

\section{(1) $\mathrm{HNO}_{3} / \mathrm{Ac}_{2} \mathrm{O}$ system}

Tang et al. [25] synthesized $1 H, 1^{\prime} H-3,3^{\prime}$-bispyrazole(20) using oxalyl chloride and ethoxyethylene as raw materials through addition, elimination, and cyclization reactions. Firstly, $100 \% \mathrm{HNO}_{3}$ was added dropwise to $\mathrm{AC}_{2} \mathrm{O}$ at $0{ }^{\circ} \mathrm{C}$, then compound 20 was slowly added to the mixed acid. The reaction mixture was warmed to room temperature, and stirred for $6 \mathrm{~h}$. The reaction mixture was subsequently poured into ice water, filtered, and washed with trifluoroacetic acid (TFAA) to obtain 1, $1^{\prime}$-dinitro- $1 H, 1^{\prime} H-3,3^{\prime}$-bispyrazole (21), with a yield of $71 \%$. The synthesis route is shown in Scheme 12.
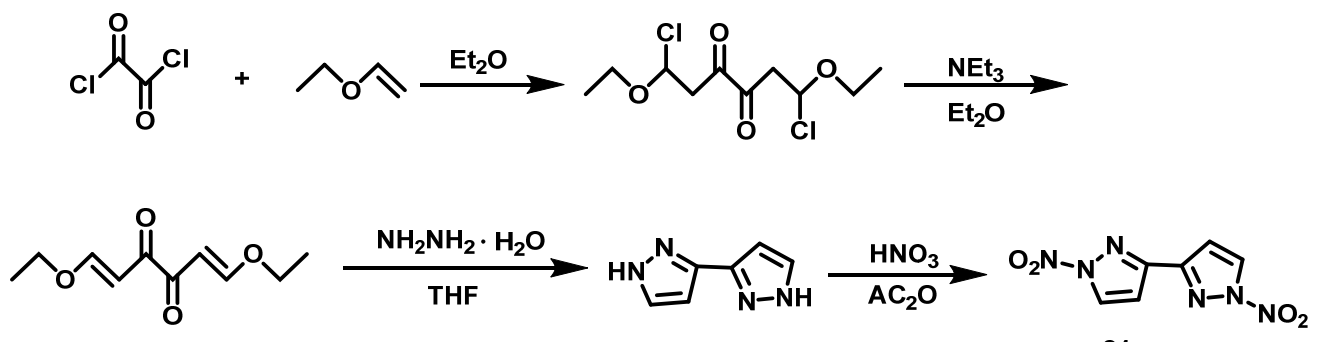

20

21

Scheme 12. Synthesis of 1,1'-dinitro- $1 H, 1 H^{\prime}-3,3^{\prime}$-bipyrazole [25].

\section{(2) $\mathrm{NH}_{4} \mathrm{NO}_{3} /$ TFAA system}

Kumar et al. [26] prepared 4, $4^{\prime}$-dinitro- $1 H, 1^{\prime} H-3,3^{\prime}$-bipyrazole (22) by nitrating bipyrazole (20) with nitric-sulfur mixed acid. Then, $\mathrm{NH}_{4} \mathrm{NO}_{3}$ was added to the suspension of compound 5 in TFAA $\left(\left(\mathrm{CF}_{3} \mathrm{CO}\right)_{2} \mathrm{O}\right)$ in batches at $0-5^{\circ} \mathrm{C}$. The reaction mixture was stirred for $5 \mathrm{~h}$ at room temperature, filtered, and washed with water to obtain 1,1 $1^{\prime}, 4,4^{\prime}$-tetranitro$1 H, 1^{\prime} H-3,3^{\prime}$-dipyrazole (23). The synthesis route is shown in Scheme $13 . \mathrm{NH}_{4} \mathrm{NO}_{3} / \mathrm{TFAA}$ are used as nitration reagents to make reaction conditions mild, and post-treatment of waste acid is not needed at the end of the reaction.

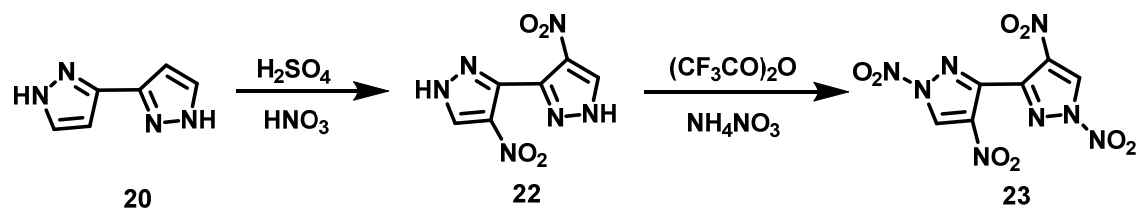

Scheme 13. Synthesis of $4,4^{\prime}, 5,5^{\prime}$-tetranitro- $2 H, 2^{\prime} H-3,3^{\prime}$-bipyrazole [26].

\subsubsection{Nitrification of $-\mathrm{NH}_{2}$ Connected with the Pyrazole Ring $\mathrm{N}$}

A fuming $\mathrm{HNO}_{3}$ / con. $\mathrm{H}_{2} \mathrm{SO}_{4}$ system can be used to nitrate $-\mathrm{NH}_{2}$ to $\mathrm{NHNO}_{2}$, which is connected with $\mathrm{N}$ in a pyrazole ring.

Yin et al. [27] cooled a concentrated $\mathrm{H}_{2} \mathrm{SO}_{4}$ suspension of 3,6-dinitropyrazole[4,3-c] pyrazole-1,4-diamine (24) to $-15{ }^{\circ} \mathrm{C}$ in an ice-salt bath, then fuming $\mathrm{HNO}_{3}$ was added dropwise to the mixture. After the mixture was stirred for $2 \mathrm{~h}$ at $-15{ }^{\circ} \mathrm{C}, N_{,}, N^{\prime}-(3,6-$ dinitropyrazole[4,3-c] pyrazole-1,4-diyl)dinitramine (25) was obtained by filtering the reaction solution and washing with TFAA. The synthesis route is shown in Scheme 14. 


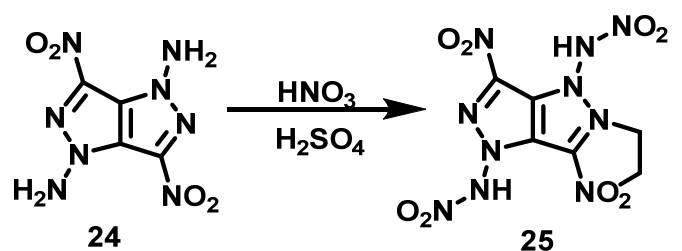

Scheme 14. Synthesis of $N, N^{\prime}$-(3,6-dinitropyrazole [4,3-c] pyrazole-1,4-diyl) dinitramine [27].

\subsection{Triazoles}

2.3.1. Nitrification of $\mathrm{H}$ on 1,2,4-Triazole Ring C

\section{(1) $70 \% \mathrm{HNO}_{3}$ system}

3-nitro-1,2,4-triazol-5-one (NTO) is a kind of insensitive high-energy explosive with excellent comprehensive performance [28,29]. The more mature synthesis method of NTO is by nitration of TO(1,2,4-triazol-5-one), which is synthesized from semicarbazide hydrochloride and formic acid using condensation and cyclization reaction. The synthesis route is shown in Scheme 15. The nitrating agent is $70 \%$ or $98 \% \mathrm{HNO}_{3}$. Huang et al. [30] added $\mathrm{TO}$ to $70 \% \mathrm{HNO}_{3}$ in batches at $60-65^{\circ} \mathrm{C}$, reacted for $1 \mathrm{~h}$, then cooled to $3{ }^{\circ} \mathrm{C}$ in an ice-water bath, filtered, and collected the $\mathrm{HNO}_{3}$ filtrate, which was recycled in the next batch of reactions. The filter cake was rinsed with water and followed by vacuum filtration. Finally, NTO was obtained via recrystallization from water with a yield of $75.4 \%$ and a purity of $99.94 \%$. Compared with the use of $98 \% \mathrm{HNO}_{3}$ as the nitrating agent, this nitration method has a simpler process, safer operation, and $\mathrm{HNO}_{3}$ filtrate can be reused, so the cost of raw materials can be lowered.

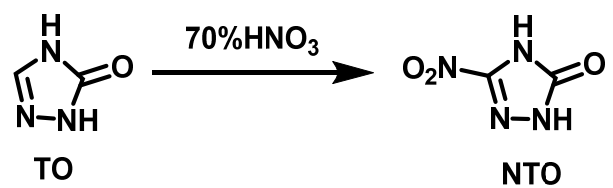

Scheme 15. Synthesis of 3-nitro-1,2,4-triazol-5-one [30].

\section{(2) $\mathrm{HNO}_{3} / \mathrm{Ac}_{2} \mathrm{O}$ system}

Aizikovich et al. [31] added $99 \% \mathrm{HNO}_{3}$ to $\mathrm{Ac}_{2} \mathrm{O}$ at $0{ }^{\circ} \mathrm{C}$ while stirring for $30 \mathrm{~min}$. The solid $N^{3}, N^{6}$-bis(1H-1,2,4-triazol-5-yl)-1,2,4,5-tetrazine-3,6-diamine (26) was slowly added to the mixture, after which, the solution was stirred for $2 \mathrm{~h}$ under anhydrous conditions. Then, the reaction solution was warmed to room temperature, filtered and washed quickly with TFAA, and immediately redissolved in hot $\mathrm{CH}_{3} \mathrm{CN}$. The obtained $\mathrm{CH}_{3} \mathrm{CN}$ solution was heated for $30 \mathrm{~min}$ at $65^{\circ} \mathrm{C}$, then cooled to room temperature. Pure $N^{3}, N^{6}$-bis(3-nitro- $1 \mathrm{H}$ 1,2,4-triazole-5-yl)-1,2,4,5-tetrazine-3,6-diamine (28) was filtrated and washed with $\mathrm{CH}_{3} \mathrm{CN}$ to give a yield of $31 \%$. The synthesis route is shown in Scheme 16. Although the yield of the reaction is low, the operation is simple with short reaction time, and the product does not need further purification.

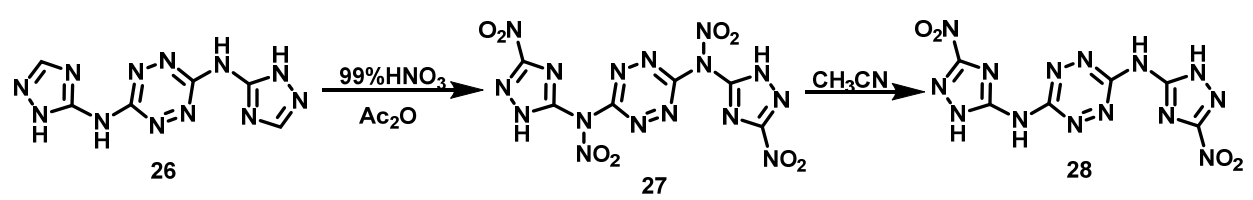

Scheme 16. Synthesis of $N^{3}, N^{6}$-Bis(3-nitro-1H-1,2,4-triazol-5-yl)-1,2,4,5-tetrazine-3,6-diamine [31].

2.3.2. Nitration of $-\mathrm{NH}_{2}$ on 1,2,4-Triazole Ring $\mathrm{C}$

(1) $\mathrm{HNO}_{3} /$ concentrated $\mathrm{H}_{2} \mathrm{SO}_{4}$ system

From the synthetic method by Astachov et al. [32], Dippold et al. [33] synthesized 3,3'-diamino-5,5'-bis (1H-1,2,4-triazole) (DABT,29) via condensation reaction using oxalic 
acid and aminoguanidine bicarbonate as raw materials. After that, $\mathrm{HNO}_{3}$ was slowly added to a concentrated $\mathrm{H}_{2} \mathrm{SO}_{4}$ solution of compound 29 at $0{ }^{\circ} \mathrm{C}$. The mixture was warmed to room temperature and stirred for $1 \mathrm{~h}$. The clear solution was then poured onto ice and the precipitate was collected by filtration. A yellow crystalline solid of 3,3'-dinitramine-5, $5^{\prime}$-bis (1H-1,2,4-triazole) (DNABT, 30) was obtained by recrystallization from boiling water with a yield of $77 \%$. The synthesis route is shown in Scheme 17.

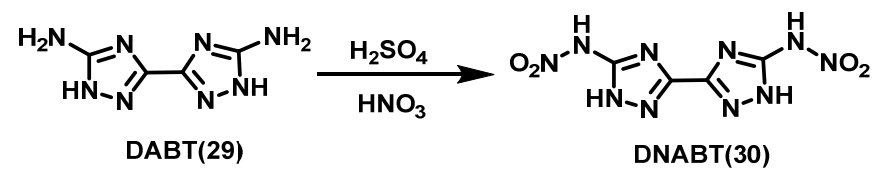

Scheme 17. Synthesis of 3,3'-dinitrimino-5, $5^{\prime}$-bis(1H-1,2,4-triazole) [33].

(2) $\mathrm{HNO}_{3} / \mathrm{P}_{2} \mathrm{O}_{5}$ system

Wang et al. [21] dissolved $\mathrm{P}_{2} \mathrm{O}_{5}$ in fuming $\mathrm{HNO}_{3}$, then (6-(3,5-dimethyl-1H-pyrazol-1yl)-1,2,4- triazole[4,3-b]-1,2,4,5-tetrazine-3-amino (31) was added to the mixture at $0{ }^{\circ} \mathrm{C}$ and stirred at room temperature for $10 \mathrm{~h}$. Then, the mixture was poured onto crushed ice and extracted with ethyl acetate, after which, $N$-(6-(3,5-dimethyl-4-nitro-1H-pyrazol-1-yl)-1,2,4triazole[4,3-b]-1,2,4,5-tetrazin-3-yl) nitramine (32) was purified by column chromatography with a yield of $58 \%$. The synthesis route is shown in Scheme 18. The nitrating reagents used in this reaction are relatively mild, but the post-treatment is relatively complicated.

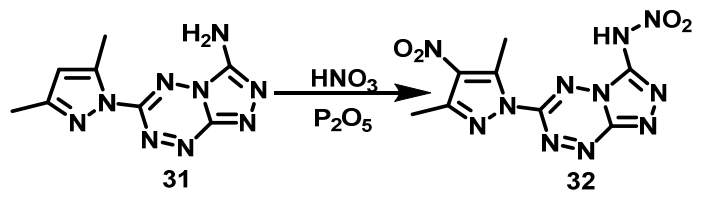

Scheme 18. Synthesis of N-(6-(3,5-dimethyl-4-nitro-1H-pyrazol-1-yl) -1,2,4-triazolo[4,3-b]-1,2,4,5tetrazin-3-yl)nitramide [21].

\subsubsection{Nitrification of $\mathrm{H}$ on 1,2,4-Triazole Ring $\mathrm{N}$}

\section{(1) $\mathrm{HNO}_{3} / \mathrm{Ac}_{2} \mathrm{O}$ system}

Yin et al. [34] dissolved TFAA and 3-nitro-1,2,4-triazole in chloroform at $0 \sim 5{ }^{\circ} \mathrm{C}$, and fuming $\mathrm{HNO}_{3}$ was added dropwise while maintaining the temperature. After the dropwise addition was completed, the reaction was warmed and stirred for $1 \mathrm{~h}$ at room temperature. The reaction solution was then poured onto crushed ice, and 1,3-dinitro- $1 H$-1,2,4-triazole (33) was obtained by extraction with chloroform with a yield of $53 \%$. The synthesis route is shown in Scheme 19.

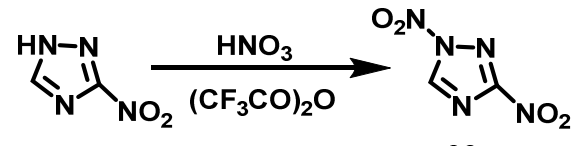

33

Scheme 19. Synthesis of 1,3-dinitro- $1 H$-1,2,4-triazole [34].

\subsubsection{Nitrification of $-\mathrm{NH}_{2}$ on 1,2,4-Triazole Ring $\mathrm{N}$}

(1) $\mathrm{HNO}_{3}$ system

Klapçtke et al. [35] synthesized 4,4',5,5'-tetraamino-3,3'-bi-1,2,4-triazole (34) using oxalic acid and diaminoguanidine hydrochloride as raw materials via a condensation reaction under the action of polyphosphoric acid. $\mathrm{HNO}_{3}$ was cooled to $-10{ }^{\circ} \mathrm{C}$ and compound 1 was slowly added while the temperature was kept below $0{ }^{\circ} \mathrm{C}$. After that, the mixture was stirred for $90 \mathrm{~min}$ at $-5^{\circ} \mathrm{C}$. Then, the solution was poured onto crushed ice, stirred for 10-15 min, filtered, and 5,5'-diamino-4, $4^{\prime}$-dinitroammonium-3,3' -di-(1,2,4triazole) (35) was obtained by washing with cold water, ethanol, and ether, respectively, 
with a yield of $69 \%$. The synthesis route is shown in Scheme 20. The synthetic method is simple in operation, and the obtained product does not require further purification.

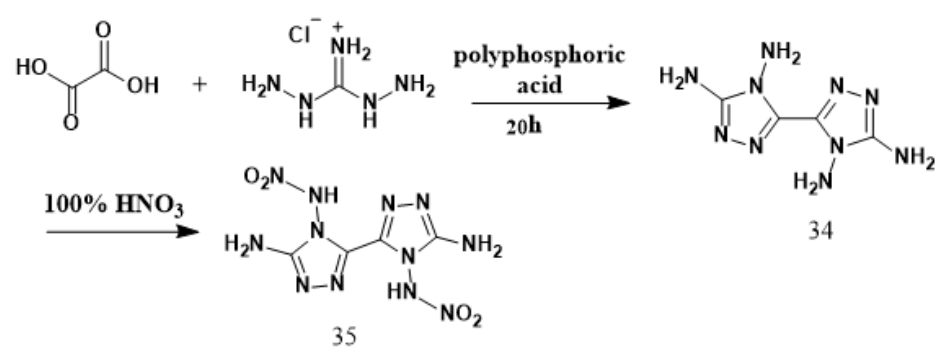

Scheme 20. Synthesis of 5,5'-diamino-4,4'-dinitramino-3,3'-bi-1,2,4-triazole [35].

\subsubsection{Nitration of $-\mathrm{NH}_{2}$ Connected with 1,2,3-Triazole Ring C}

Zhang et al. [36] added 4-amino-5-nitro-1,2,3-2H-triazole (36) to a mixture of $\mathrm{HNO}_{3}$ (70\%) and concentrated $\mathrm{H}_{2} \mathrm{SO}_{4}$ in batches and stirred for $2 \mathrm{~h}$ at $0{ }^{\circ} \mathrm{C}$. After stirring for another $2 \mathrm{~h}$ at room temperature, the reaction mixture was poured into ice water. 4 nitramine-5-nitro-1,2,3-2H-triazole (37) was obtained by ether extraction, and the yield was $76 \%$. The synthesis route is shown in Scheme 21.

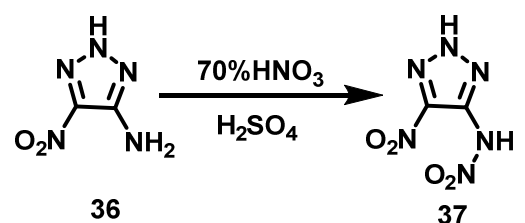

Scheme 21. Synthesis of 4-nitramino-5-nitro-1,2,3-2H-triazole [36].

\subsubsection{Nitrification of $\mathrm{H}$ on 1,2,3-Triazole Ring $\mathrm{N}$}

Thottempudi et al. [37] added concentrated $\mathrm{HNO}_{3}$ to $\mathrm{Ac}_{2} \mathrm{O}$ dropwise at $-5{ }^{\circ} \mathrm{C}$, the mixture was stirred for $30 \mathrm{~min}$, and then stirred for another $45 \mathrm{~min}$ at room temperature. Subsequently, the mixture was cooled to $-5^{\circ} \mathrm{C}$, and tris(triazolo) benzene (38) was added in portions, stirred for about $15 \mathrm{~min}$, and stirred overnight at room temperature. The mixture was then poured onto ice, filtered, and washed with water to obtain the final product of trinitrotris(triazolo)benzene (39) with a yield of 53\%. The synthesis route is shown in Scheme 22.

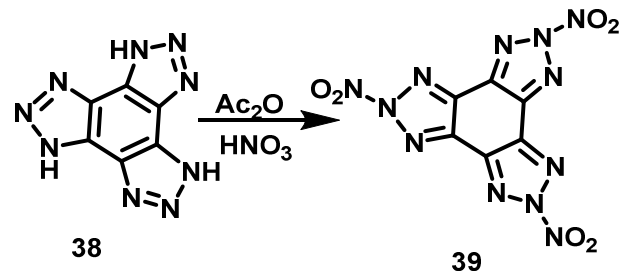

Scheme 22. Synthesis of 2,5,8-trinitrotris(triazolo)benzene [37].

\subsection{Tetrazoles}

\subsubsection{Nitrification of $-\mathrm{NH}_{2}$ on Tetrazole C}

\section{(1) $\mathrm{NO}_{2} \mathrm{BF}_{4}$ system}

Stierstorfer et al. [38] dissolved 1-(2-azidoethyl)-5-aminotetrazole (40) in MeCN in an ice-water bath, and added nitronium tetrafluoroborate $\left(\mathrm{NO}_{2} \mathrm{BF}_{4}\right)$ to the solution. The solution was then stirred for $30 \mathrm{~min}$ at $0{ }^{\circ} \mathrm{C}$ and for another $1 \mathrm{~h}$ at $25^{\circ} \mathrm{C}$. The solvent was evaporated and $\mathrm{KOH}$ ethanol solution was added. The precipitated $\mathrm{KBF}_{4}$ was removed by filtration and another equivalent of $\mathrm{KOH}$ in ethanol was added. The solvent was evaporated and cold water was added. The insoluble material was removed by filtration and the water was evaporated. Potassium 1-(2-azidoethyl)-5-nitroaminotetrazole (41) was 
finally obtained by recrystallization from hot ethanol with a yield of $33 \%$. After that, an equimolar amount of dilute $(1 \mathrm{~N}) \mathrm{HCl}$ was added to compound 41 . Then, the solvent was evaporated and acetone was added to the residue. The solution was filtered to remove $\mathrm{KCl}$. After acetone was evaporated, the crude product was recrystallized from a small amount of methanol to yield colorless 42 (90\%). The synthesis route is shown in Scheme 23. The reaction conditions are mild and the temperature is easy to control. However, $\mathrm{HBF}_{4}$ must be removed after the reaction, the yield of compound 41 is low, and the purification is difficult.

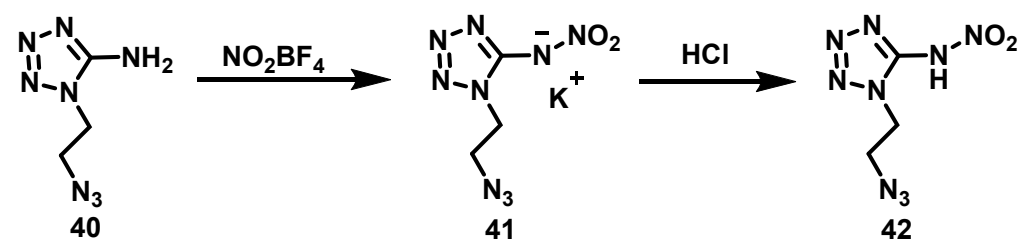

Scheme 23. Synthesis of 1-(2-azidoethyl)-5-nitriminotetrazole [38].

\section{(2) $\mathrm{N}_{2} \mathrm{O}_{5}$ system}

Fischer et al. [39] synthesized 1-methoxycarbonyl-1,5-diaminotetrazole (43) using dimethyl carbonate via nucleophilic substitution and a ring formation reaction. After that, compound 43 was suspended in anhydrous acetonitrile at $0{ }^{\circ} \mathrm{C}$, a solution of $\mathrm{N}_{2} \mathrm{O}_{5}$ in acetonitrile $(\mathrm{MeCN})$ was added, and the mixture was stirred for $1 \mathrm{~h}$. $\mathrm{KOH}$ aqueous solution was then added dropwise, the aqueous phase was separated, and the water was evaporated under high vacuum. The residue was stirred in methanol for several hours. The reaction solution was filtered, washed with methanol, and dried. The obtained solid was dissolved in $2 \mathrm{M} \mathrm{HCl}$, and 1,5-bis(nitroamino)tetrazole (46) was obtained by extraction with ethyl acetate in a yield of $50 \%$. The synthesis route is shown in Scheme 24 . The reaction has less heat generation and the temperature is easy to control. Moreover, the product separation is simple with no waste acid treatment.

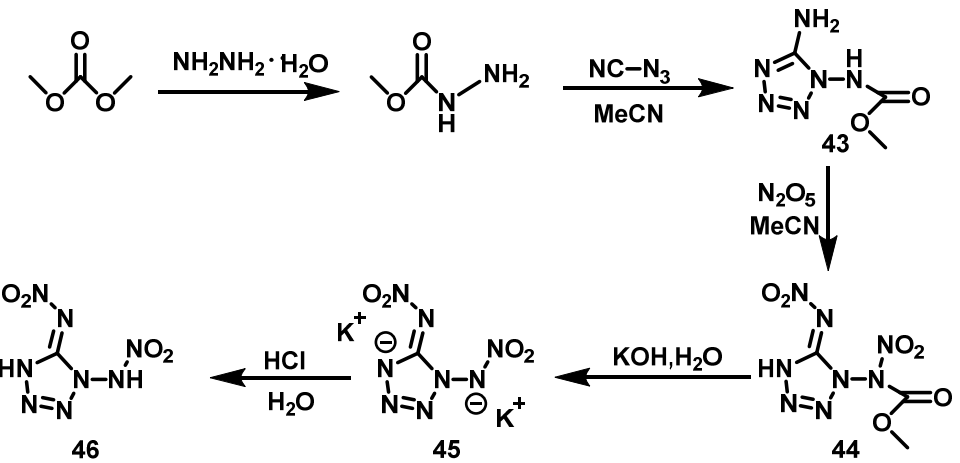

Scheme 24. Synthesis of 1,5-di(nitramino)tetrazole [39].

\section{(3) $100 \% \mathrm{HNO}_{3}$ system}

Kumar et al. [40] synthesized amino 1-((1H-tetrazol-5-yl)methyl)-1H-tetrazole-5-amino (48) using aminoacetonitrile hydrochloride and cyanide azide (47) as raw materials through two-step ring formation reaction. Then, compound 2 was slowly added to $100 \% \mathrm{HNO}_{3}$ at $0-2{ }^{\circ} \mathrm{C}$. After stirring for $12 \mathrm{~h}$ at room temperature, the mixture was poured into cold water. Thus, $N$-(1-((1H-tetrazol-5-yl)methyl)- $1 H$-tetrazole-5 (4H)-alkylene)nitramine (49) was obtained by extraction with ethyl acetate in a yield of $65 \%$. The synthesis route is shown in Scheme 25. 

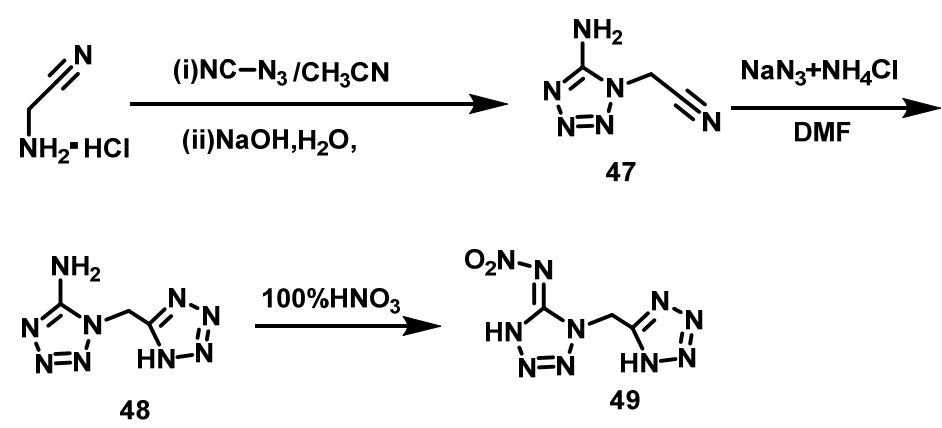

Scheme 25. Synthesis of $N-(1-((1 H$-tetrazol-5-yl)methyl)-1H-tetrazol-5(4H)-ylidene)nitramide [40].

\subsubsection{Nitrification of $-\mathrm{NH}_{2}$ Connected with Tetrazole Ring $\mathrm{N}$}

(1) $\mathrm{NO}_{2} \mathrm{BF}_{4}$ system

Klapçtke et al. [41] dissolved 1,5-diaminotetrazole in anhydrous acetonitrile at $0{ }^{\circ} \mathrm{C}$ and added $\mathrm{NO}_{2} \mathrm{BF}_{4}$ to the solution with stirring. The reaction mixture was then stirred overnight at room temperature. A pale yellow solid was obtained by evaporating acetonitrile under vacuum. The solid was re-dissolved in a small amount of ethanol, and then a mixed solution of $\mathrm{KOH}$ and ethanol was added to precipitate potassium tetrafluoroborate. Followed by filtration, the filtrate was evaporated and 5-amino-1-nitroaminotetrazole $\left(\mathrm{HDATNO}_{2}, 50\right)$ was obtained with a yield of $59 \%$. The synthesis route is shown in Scheme 26. The nitrating agent, $\mathrm{NO}_{2} \mathrm{BF}_{4}$, is environmentally friendly and does not require waste acid treatment. The reaction conditions are mild and the temperature is easy to control. There are fewer byproducts in the reaction and the selectivity of the reaction is high, but $\mathrm{NO}_{2} \mathrm{BF}_{4}$ is expensive and has high costs.

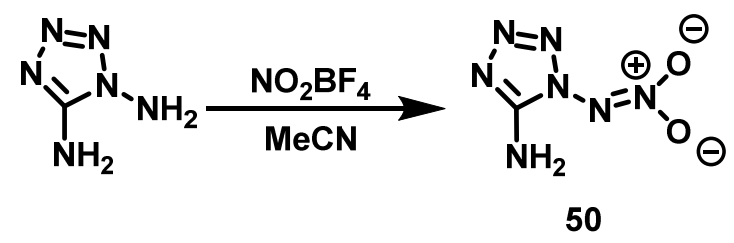

Scheme 26. Synthesis of 5-amino-1-nitriminotetrazole [41].

(2) $\mathrm{N}_{2} \mathrm{O}_{5}$ system

Fischer et al. [42] suspended 1,1'-diamino-5,5'-azobitetrazole (51) in dry acetonitrile at $0{ }^{\circ} \mathrm{C}$ and added a solution of $\mathrm{N}_{2} \mathrm{O}_{5}$ in cold acetonitrile dropwise. The $\mathrm{KOH}$ solution was added dropwise until 1,1'-diamino-5,5'-azobitetrazole was dissolved, and then the red crystal of 1,1'-dinitroammonium-5,5'-azobitetrazole dipotassium salt (52) was obtained via filtration. The yield was $62 \%$. Subsequently, the salt 4 was dissolved in $2 \mathrm{M} \mathrm{HCl}$, and a colorless single crystal of 1,1'-dinitroammonium-5,5'-azotetrazole (53) was obtained via extraction with ethyl acetate. The synthesis route is shown in Scheme 27. This reaction uses $\mathrm{N}_{2} \mathrm{O}_{5}$ as a nitration system, which has higher nitration selectivity, less side reactions, superior yield, and lower equipment requirements, thereby reducing the cost of the entire process.

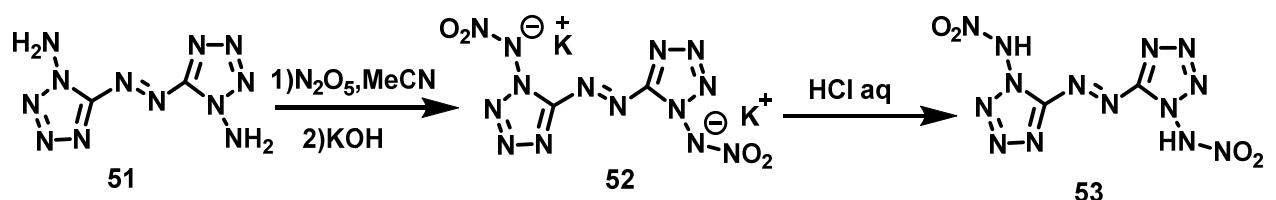

Scheme 27. Synthesis of 1,1'-dinitramino-5,5'-azobitetrazole [42]. 


\subsection{Oxadiazoles}

\subsubsection{Nitration of $-\mathrm{NH}_{2}$ on $1,2,4$-Oxadiazole Ring $\mathrm{C}$}

(1) $100 \% \mathrm{HNO}_{3}$ system

Tang et al. [43] slowly added 5,5'-diamino-3,3'-azo-1,2,4-oxadiazole (54) to $100 \% \mathrm{HNO}_{3}$ at $-5^{\circ} \mathrm{C}$ and then slowly raised the temperature to room temperature. The mixture was stirred overnight. 5,5'-dinitroammonium-3,3'-azo-1,2,4-oxadiazole (55) was obtained via filtration and washed with TFAA, with a yield of 75\%. The synthesis route is shown in Scheme 28 . The reaction yield is high and the obtained product is pure without further purification.

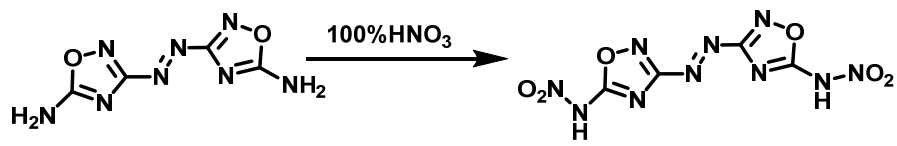

55

Scheme 28. Synthesis of 5,5'-dinitramino-3,3'-azo-1,2,4-oxadiazole [43].

\section{(2) $\mathrm{HNO}_{3} / \mathrm{Ac}_{2} \mathrm{O}$ system}

Tang et al. [44] synthesized 3-amino-5- $\mathrm{N}$-ethoxychloroamido-1,2,4-oxadiazole hydrochloride (56) using the sodium salt of malononitrile and hydroxylamine as raw materials (Scheme 29) through a ring formation reaction and substitution reaction. $\mathrm{HNO}_{3}(100 \%)$ was slowly added to the acetic anhydride at $0{ }^{\circ} \mathrm{C}$. Compound 56 was then added to the mixture and stirred for $1 \mathrm{~h}$. Afterwards, the reaction solution was poured into ice water. The pure product of 3-amino-5- $\mathrm{N}$-nitro-ethoxyformamido-1,2,4-oxadiazole (57) was obtained via filtration and washing with cold water. The yield was $73 \%$. Subsequently, compound 57 was treated with a solution of hydrazine in acetonitrile to obtain 3-amino-5-nitroamino1,2,4-oxadiazole hydrazine salt (58). 3-amino-5- nitroamino-1,2,4-oxadiazole monohydrate (59) was obtained via acidification with concentrated hydrochloric acid.

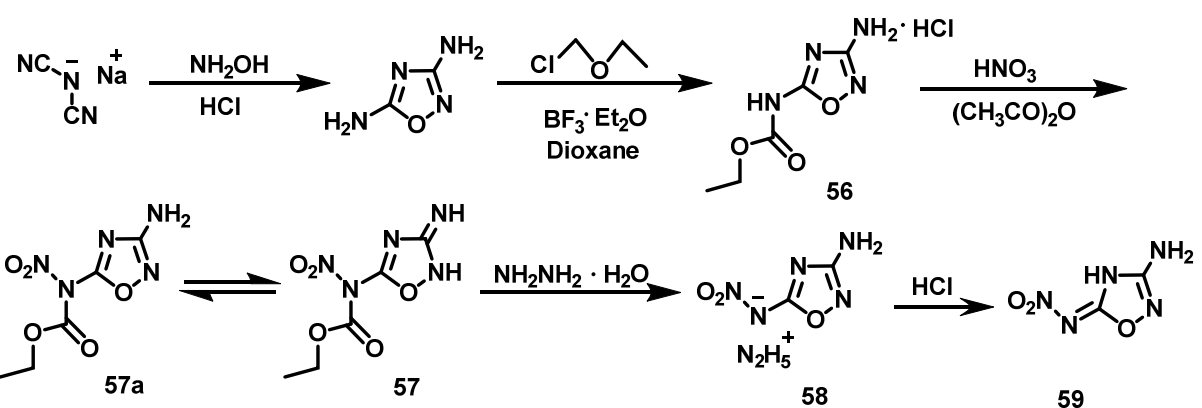

Scheme 29. Synthesis of 3-amino-5-nitramino-1,2,4-oxadiazole monohydrate [44].

\subsubsection{Nitrification of $-\mathrm{NH}_{2}$ on 1,3,4-Oxadiazole Ring $\mathrm{C}$}

(1) $100 \% \mathrm{HNO}_{3}$ system

Tobias et al. [45] synthesized intermediate 2,2'-diamino-5,5'-bis(1-3,4-oxadiazole) (60) using oxalodiazide and $\mathrm{BrCN}$ as raw materials. Compound 60 was added to $100 \% \mathrm{HNO}_{3}$ in portions at $0{ }^{\circ} \mathrm{C}$, and the mixture was stirred for $12 \mathrm{~h}$ at room temperature. 2,2'dinitroamino-5,5-bi(1-3,4-oxadiazole) (61) was obtained by filtering and washing with water, methanol, and ether, respectively, with a yield of $84 \%$. The synthesis route is shown in Scheme 30. In this reaction, $100 \% \mathrm{HNO}_{3}$ is used as a nitrating agent, and the yield is greater than $80 \%$ with a high purity of the nitrated product.

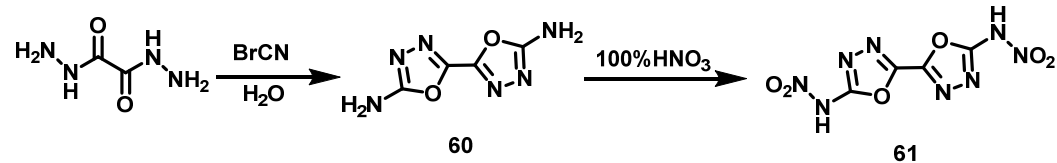

Scheme 30. Synthesis of 2,2'-dinitramino-5,5-bi(1-oxa-3,4-diazole) [45]. 


\subsubsection{Nitration of $-\mathrm{NH}_{2}$ Connected with 1,2,5-Oxadiazole(Furazan) Ring C}

(1) $\mathrm{N}_{2} \mathrm{O}_{4} / 100 \% \mathrm{HNO}_{3}$ system

Sheremetev et al. [46] added 3-amino-4-methylfurazan (62) to a mixture of $100 \% \mathrm{HNO}_{3}$ and $2 \% \mathrm{~N}_{2} \mathrm{O}_{4}$ at $-5{ }^{\circ} \mathrm{C}$, and stirred for $1 \mathrm{~h}$. Then, the reaction mixture was heated to $20^{\circ} \mathrm{C}$ and poured onto ice. 3-nitroamino-4-methylfurazan (63) was obtained via extraction with diethyl ether, washing with cold water, and drying with $\mathrm{MgSO}_{4}$, with a yield of $40-45 \%$. The synthesis route is shown in Scheme 31.

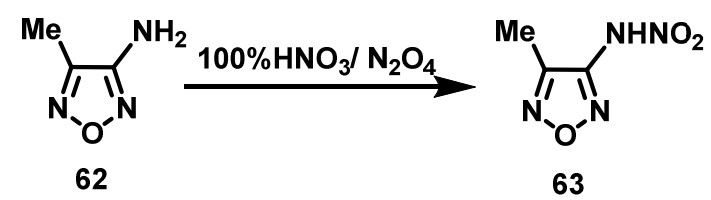

Scheme 31. Synthesis of 3-nitroamino-4 -methylfurazan with $\mathrm{N}_{2} \mathrm{O}_{4} / 100 \% \mathrm{HNO}_{3}$ system [46].

\section{(2) $\mathrm{NO}_{2} \mathrm{BF}_{4}$ system}

Sheremetev et al. [46] also added 3-amino-4-methylfurazan (62) to a $\mathrm{CH}_{2} \mathrm{Cl}_{2}$ suspension of $\mathrm{NO}_{2} \mathrm{BF}_{4}$. The mixture was cooled to $0{ }^{\circ} \mathrm{C}$, stirred for $1 \mathrm{~h}$, and then the temperature was slowly raised to $5^{\circ} \mathrm{C}$. Subsequently, the reaction mixture was poured onto ice, and the resulting emulsion was extracted with diethyl ether to obtain 3-nitroamino-4-methylfurazan (63) in a 63\% yield. The synthesis route is shown in Scheme 32.

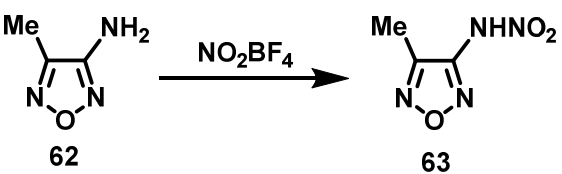

Scheme 32. Synthesis of 3-nitroamino-4 -methylfurazan with $\mathrm{NO}_{2} \mathrm{BF}_{4}$ system [46].

\section{(3) $100 \% \mathrm{HNO}_{3}$ system}

Fischer et al. [47] synthesized 3,3'-diamino-4,4'-bifurazan (64) using glyoxal and hydroxylamine by nucleophilic addition, chlorination, substitution, nucleophilic addition, and cyclization reactions. Then, compound 64 was slowly added to $100 \% \mathrm{HNO}_{3}$ at $-5{ }^{\circ} \mathrm{C}$ to $0{ }^{\circ} \mathrm{C}$, and stirred for $45 \mathrm{~min}$. The suspension was poured onto ice and 3,3'-dinitroamino$4,4^{\prime}$-furazan (65) was obtained by filtering and washing with ice water, with a yield of $80 \%$. The synthesis route is shown in Scheme 33. The yield can be increased to more than $90 \%$ by using an organic solvent (such as ethyl acetate) to extract filtrate.
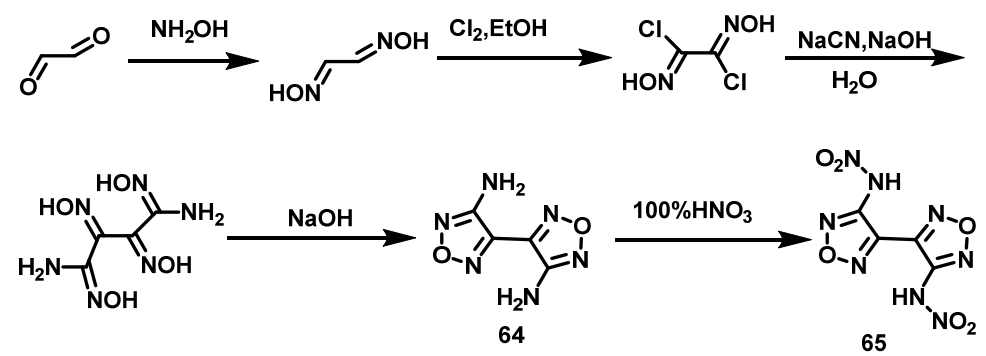

Scheme 33. Synthesis of 3,3'-dinitramino-4,4'-bifurazane [47].

\section{(4) $\mathrm{HNO}_{3} / \mathrm{Ac}_{2} \mathrm{O}$ system}

Zhang et al. [48] added compound (66) in batches to a mixture of acetic anhydride and $100 \% \mathrm{HNO}_{3}$ at $0{ }^{\circ} \mathrm{C}$. The reaction mixture was stirred for $6 \mathrm{~h}$ at room temperature and then poured into ice water. $N, N^{\prime}$-dinitro- $N, N^{\prime}$-bis [3-(methyl-azo-nitrogen oxide) furazan-4-yl] methylene diamine (67) was obtained by filtering and washing the precipitate with ethanol in a yield of $66 \%$. The synthesis route is shown in Scheme 34. In this nitration system, 
the acid anhydride can effectively reduce the oxidizing property of $\mathrm{HNO}_{3}$, preventing the generation of by-products. The reaction has simple operation procedures and a high yield.

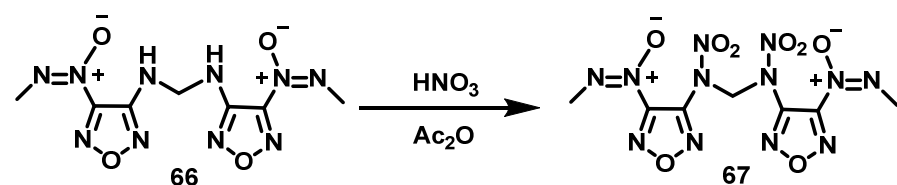

Scheme 34. Synthesis of $N, N^{\prime}$-dinitro- $N, N^{\prime}$-bis[3-(methyl-NNO-azoxy)furazan-4-yl]methylenediamine [48].

\section{(5) $\mathrm{N}_{2} \mathrm{O}_{5}$ system}

Klapötke et al. [49] cooled dichloromethane $\left(\mathrm{CH}_{2} \mathrm{Cl}_{2}\right)$ to $-20{ }^{\circ} \mathrm{C}$ and added $\mathrm{N}_{2} \mathrm{O}_{5}$, while keeping the temperature at $-20^{\circ} \mathrm{C}$. After it was completely dissolved, 3-amino-4nitrofurazan was slowly added at $-20^{\circ} \mathrm{C}$. The solution was slowly warmed up to $0-5{ }^{\circ} \mathrm{C}$ and stirred for $3 \mathrm{~h}$. The solvent was removed under a constant nitrogen stream until most of the solvent was removed and 3-nitramino-4-nitrofurazan (68) was obtained in a yield of $66 \%$. The synthesis route is shown in Scheme 35.

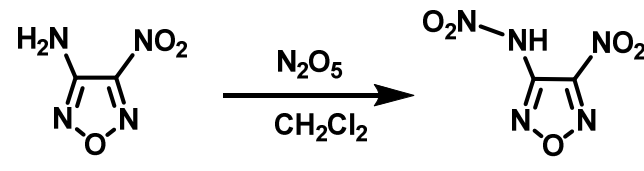

68

Scheme 35. Synthesis of 3-nitramino-4-nitrofurazan [49].

\section{Nitrification of Azines as Nitrogen-Rich Heterocyclic Energetic Compounds}

\subsection{Pyridazines}

Nitrification of H on Pyridazine Ring C

Gospodinov et al. [50] prepared the compound 3,5-dimethoxypyridazine-1-oxide (69) using dichloropyridazine as a raw material by substitution reaction and oxidation reaction, and then used two nitration systems to obtain compound $\mathbf{7 0}$. The synthesis route is shown in Scheme 36.
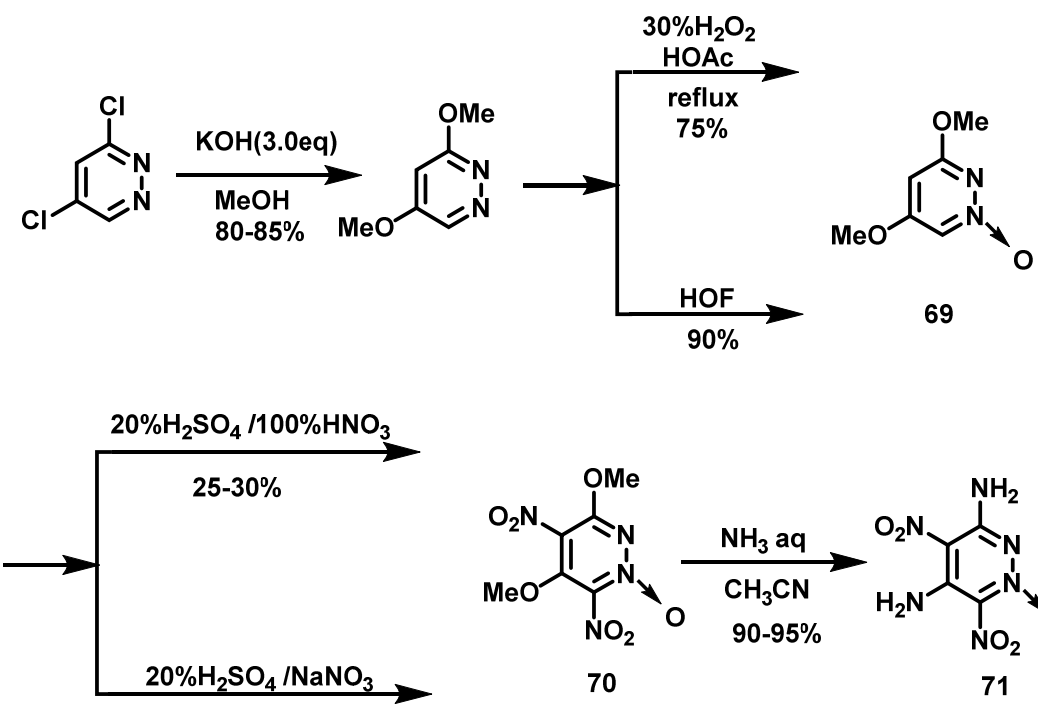

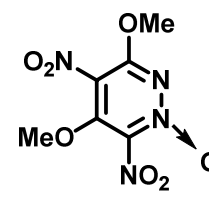

70

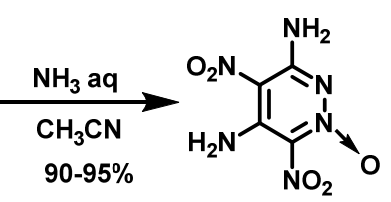

71

$13 \%$

Scheme 36. Synthesis of 3,6-diamino-4,6-dinitropyridazine-1-oxide [50].

(1) $20 \% \mathrm{H}_{2} \mathrm{SO}_{4} / 100 \% \mathrm{HNO}_{3}$ system

Compound 69 was dissolved in $20 \%$ fuming $\mathrm{H}_{2} \mathrm{SO}_{4}$ at $5{ }^{\circ} \mathrm{C}$, after which, $\mathrm{NaNO}_{3}$ was added in batches, the reaction mixture was stirred for $1 \mathrm{~h}$, and was then slowly warmed up to room temperature. After that, the reaction mixture was stirred overnight at $60{ }^{\circ} \mathrm{C}$ 
and then poured onto crushed ice. The resulting suspension was stirred until the ice dissolved and the resulting precipitate was filtered. The crude product was dissolved in conc. $\mathrm{H}_{2} \mathrm{SO}_{4}$, stirred for $3 \mathrm{~h}$ at $60{ }^{\circ} \mathrm{C}$, and then poured on ice and the precipitate was filtered. 3,5-dimethoxy-4,6-dinitropyridazine-1-oxide (70) was obtained after washing with ice water several times in a yield of $13 \%$.

\section{(2) $20 \% \mathrm{H}_{2} \mathrm{SO}_{4} / 100 \% \mathrm{NaNO}_{3}$ system}

Compound 69 was dissolved in $20-25 \%$ fuming $\mathrm{H}_{2} \mathrm{SO}_{4}$ at $10{ }^{\circ} \mathrm{C}$, and $100 \% \mathrm{HNO}_{3}$ was added dropwise below $8{ }^{\circ} \mathrm{C}$. The reaction mixture was first stirred at $0{ }^{\circ} \mathrm{C}$ for $1.5 \mathrm{~h}$, then at room temperature for $2 \mathrm{~h}$, and finally stirred at $45-50{ }^{\circ} \mathrm{C}$ for $20 \mathrm{~h}$. After cooling, the reaction was poured onto crushed ice. The resulting suspension was stirred for $2 \mathrm{~h}$ and the obtained yellowish precipitate was filtered off and washed with water. The crude product was dissolved in conc. $\mathrm{H}_{2} \mathrm{SO}_{4}$ and stirred at $60{ }^{\circ} \mathrm{C}$ for $2 \mathrm{~h}$. The mixture was poured onto crushed ice, filtered, and washed with ice water to obtain compound $\mathbf{7 0}$ in a yield of 28\%. Finally, 3,6-diamino-4,6-dinitropyridazine-1-oxide (71) was synthesized by reacting compound 70 with concentrated ammonia in acetonitrile solution.

\subsection{Pyrazines}

Nitrification of H on Pyrazine Ring C

The density of 2,6-diamino-3,5-dinitropyrazine-1-oxide (LLM-105, 73) is $1.92 \mathrm{~g} \cdot \mathrm{cm}^{-3}$ with the detonation velocity of $8516 \mathrm{~m} \cdot \mathrm{s}^{-1}$ and the detonation pressure of $35.9 \mathrm{GPa}$. It is a new explosive with excellent energy and safety performance. In the process of its preparation, there is a typical nitration reaction of $\mathrm{H}$ on pyrazine $\mathrm{C}$, and the preparation method of LLM-105 has been improving. In 2014, Zhou et al. [51] used two nitration systems to nitrate the intermediate 2,6-diacetamidopyrazine-1-oxide (72) to obtain LLM-105. The synthesis route is shown in Scheme 37.
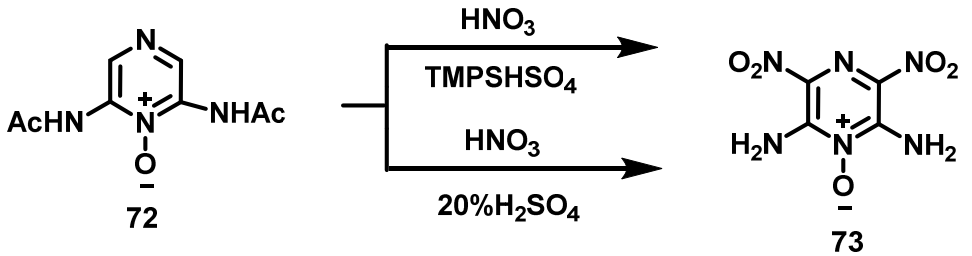

Scheme 37. Synthesis of 2,6-diamino-3,5-dinitropyrazine-1-oxide [51].

\section{(1) $20 \% \mathrm{H}_{2} \mathrm{SO}_{4} / 100 \% \mathrm{HNO}_{3}$ system}

Compound 72 was added into $20 \%$ fuming $\mathrm{H}_{2} \mathrm{SO}_{4}$ when the temperature was lower than $25^{\circ} \mathrm{C}$, the temperature of the mixture was controlled to be lower than $10^{\circ} \mathrm{C}$ at the end of feeding, and then fuming $\mathrm{HNO}_{3}$ was slowly added into the mixture. Afterwards, the system was controlled to react for $1 \mathrm{~h}$ within $10-15^{\circ} \mathrm{C}$ and then heated to room temperature for $2 \mathrm{~h}$. Finally, the mixture was poured onto crushed ice, filtered, washed with water, and dried to obtain the bright yellow LLM-105 solid with the yield of $72 \%$.

(2) $100 \% \mathrm{HNO}_{3} / \mathrm{TMPSHSO}_{4}$ system

$N, N, N$-trimethyl- $N$-propanesulfonate-ammonium bisulfate $\left(\mathrm{TMPSHSO}_{4}\right)$, as an ionic liquid, was dissolved in fuming $\mathrm{HNO}_{3}$, cooled to about $0{ }^{\circ} \mathrm{C}$, and then compound 72 was slowly added. The reaction solution was stirred for $0.5 \mathrm{~h}$; then heated to $25^{\circ} \mathrm{C}$, reacting for $1 \mathrm{~h}$; and heated to $75^{\circ} \mathrm{C}$, reacting for $4 \mathrm{~h}$. After the reaction was completed, the mixture was cooled to room temperature, diluted with distilled water, filtered and washed with water three times, and dried to obtain yellow LLM-105, with a yield of $68.4 \%$. Compared with nitration with mixed acid, $\mathrm{HNO}_{3}$ /acid ionic liquid has the advantages of simpler post-treatment and less waste acid discharge. 


\section{(3) $\mathrm{H}_{2} \mathrm{SO}_{4} / 95 \% \mathrm{HNO}_{3}$ system}

Liu et al. [52] synthesized 2,6-dipyramidopyrazine (74) using 2,4,6-trinitrochlorobenzene and 2,6-diaminopyrazine by condensation reaction. Next, 95\% fuming $\mathrm{HNO}_{3}$ and concentrated $\mathrm{H}_{2} \mathrm{SO}_{4}$ were stirred for $0.5 \mathrm{~h}$ at $0{ }^{\circ} \mathrm{C}$. After that, compound 74 was slowly added, and then the temperature was gradually raised to $50{ }^{\circ} \mathrm{C}$ for $3 \mathrm{~h}$. Subsequently, the reaction solution was cooled, poured into ice water, filtered and washed with acetone, and dried in a vacuum to obtain 2,6-dipyramido-3,5-dinitro- pyrazine (BPNP, 75). The yield was $66 \%$. The synthesis route is shown in Scheme 38.
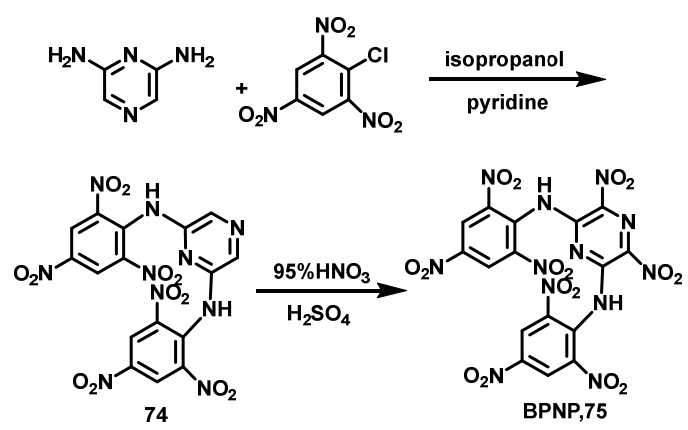

Scheme 38. Synthesis of BPNP [52].

\subsection{Nitrification of $-\mathrm{NH}_{2}$ Connected with Triazine Ring $\mathrm{C}$}

Huang et al. [53] synthesized 6-amino-2,4-diazio[1,3,5]triazine (76) using cyanuric acid chloride with aqueous $\mathrm{NH}_{3}$ at $0{ }^{\circ} \mathrm{C}$ and then sodium azide in acetone $/ \mathrm{H}_{2} \mathrm{O}(1: 1)$. After that, compound (76) was added to $\mathrm{HNO}_{3}(100 \%)$ in batches below $5{ }^{\circ} \mathrm{C}$, after which the reaction mixture was stirred for $30 \mathrm{~min}$ at $0{ }^{\circ} \mathrm{C}$, slowly warmed up to room temperature, and stirred for another $3 \mathrm{~h}$. Afterwards, the reaction mixture was poured onto ice, filtered, washed with cold water, and dried in air to obtain 2-nitroamino-4,6-diazo[1,3,5]triazine (77) in a yield of $54 \%$. The synthesis route is shown in Scheme 39.

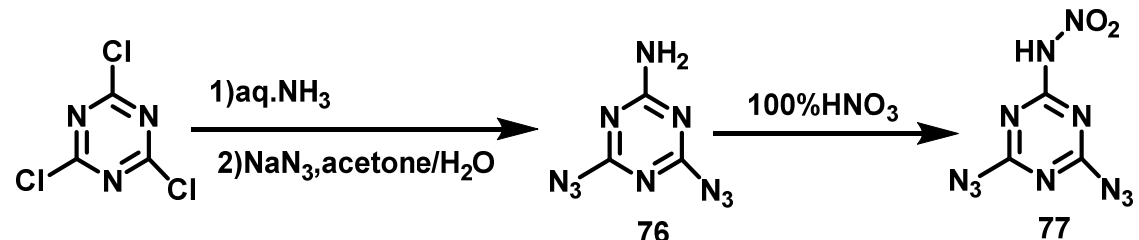

Scheme 39. Synthesis of 2-Nitroamino-4,6-diazido[1,3,5]triazine [53].

\subsection{Nitrification of $-\mathrm{NH}_{2}$ on Tetrazine Ring $\mathrm{C}$}

Zhang et al. [54] added 3,6-diamino-1,2,4,5-tetrazine to fuming $\mathrm{HNO}_{3}$ at $0{ }^{\circ} \mathrm{C}$, then gradually stirred for $1 \mathrm{~h}$, filtered, and dried. 3,6-dinitroamino-1,2,4,5-tetrazine (DNAT, 78) was obtained by recrystallization from ethyl acetate with $85.0 \%$ yield. The synthesis route is shown in Scheme 40.

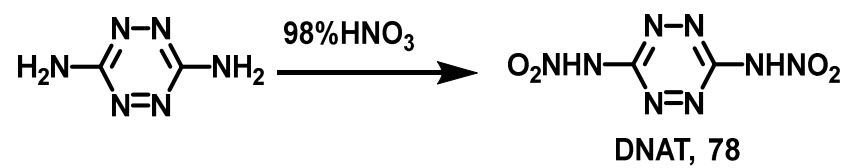

Scheme 40. Synthesis of 3,6-dinitroamine-1,2,4,5-tetrazine [54].

\section{Conclusions}

The characteristics of the used nitration agents are listed in Table 1. 
Table 1. Characteristics of different nitrification systems.

\begin{tabular}{|c|c|}
\hline Nitrification System & Characteristic \\
\hline $\mathrm{HNO}_{3}$ & $\begin{array}{l}\text { Cheap. To nitrate different azole rings, different concentrations of } \mathrm{HNO}_{3} \\
\text { are required. }\end{array}$ \\
\hline $\mathrm{HNO}_{3} / \mathrm{H}_{2} \mathrm{SO}_{4}$ & $\begin{array}{l}\text { The nitration ability is stronger than that of } \mathrm{HNO}_{3} \text {, and it is often used } \\
\text { for the nitration of a variety of azole compounds. According to the } \\
\text { structural characteristics of different azole rings and the difficulty of the } \\
\text { aromatic electrophilic substitution reaction, a suitable ratio of } \\
\mathrm{HNO}_{3} / \mathrm{H}_{2} \mathrm{SO}_{4} \text { should be selected for nitration. The reaction conditions } \\
\text { are mostly mild, the required temperature range is generally from } 20^{\circ} \mathrm{C} \\
\text { to } 100{ }^{\circ} \mathrm{C} \text {, the reaction time is about } 1 \mathrm{~h} \text { to } 2.5 \mathrm{~h} \text {, and the yield can reach } \\
\text { about } 80 \% \text { or higher. For some azole substrates with relatively inert } \\
\text { reaction activity (such as the existence of strong electron-withdrawing } \\
\text { group), the reaction rate is generally slow and the reaction time needs to } \\
\text { be extended to } 10-48 \mathrm{~h} \text {. }\end{array}$ \\
\hline $\mathrm{HNO}_{3} / \mathrm{Ac}_{2} \mathrm{O}$ & $\begin{array}{l}\text { Compared with the nitrating reagent } \mathrm{HNO}_{3} / \mathrm{H}_{2} \mathrm{SO}_{4} \text {, the } \mathrm{HNO}_{3} / \mathrm{Ac}_{2} \mathrm{O} \\
\text { mixture has a weaker nitrification ability, but the acid anhydride can } \\
\text { effectively reduce the oxidation of } \mathrm{HNO}_{3} \text {. }\end{array}$ \\
\hline $\mathrm{NO}_{2} \mathrm{BF}_{4}$ & $\begin{array}{l}\text { An environmentally friendly nitrating reagent without waste acid } \\
\text { treatment. The reaction condition is relatively mild, and the temperature } \\
\text { is easy to control. It is non-oxidizing and has high reaction selectivity. It } \\
\text { can be used for the aromatic electrophilic nitration reaction of various } \\
\text { azole rings, acetonitrile is often used as the solvent, the reaction time is } \\
\text { generally } 10 \mathrm{~h} \text {, and the yield is } 30-50 \% \text {. }\end{array}$ \\
\hline $\mathrm{N}_{2} \mathrm{O}_{5}$ & $\begin{array}{l}\mathrm{N}_{2} \mathrm{O}_{5} \text { is a green nitrification reagent that can be used for the nitration of } \\
\text { sensitive compounds. Compared with nitration reagents such as } \mathrm{HNO}_{3} \text {, } \\
\mathrm{HNO}_{3} / \mathrm{H}_{2} \mathrm{SO}_{4}, \mathrm{HNO}_{3} / \text { acid anhydride, it has the following advantages: } \\
\text { no need for waste acid treatment, the reaction has less heat release and } \\
\text { the temperature is easy to control, the post-treatment is simple as only } \\
\text { the solvent needs to be evaporated, the reaction is usually carried out } \\
\text { with } \mathrm{CH}_{2} \mathrm{Cl}_{2} \text { as solvent, the temperature is generally from } 20{ }^{\circ} \mathrm{C} \text { to } 100 \\
{ }^{\circ} \mathrm{C} \text {, and the yield is about } 90 \% \text {. }\end{array}$ \\
\hline $\mathrm{HNO}_{3} / \mathrm{P}_{2} \mathrm{O}_{5}$ & $\begin{array}{l}\text { In this system, } \mathrm{P}_{2} \mathrm{O}_{5} \text { is not only a dehydrating agent, but also a } \\
\text { nitrification accelerator. The nitration system is suitable for the nitration } \\
\text { of aromatics as well as amines. }\end{array}$ \\
\hline Nitrate & $\begin{array}{l}\text { Under catalysis, some nitrates can also act as nitrating reagents, which } \\
\text { are mainly used in the synthesis of some nitropyrazole compounds. } \\
\text { Their nitrating capacities are as follows: } \mathrm{Bi}\left(\mathrm{NO}_{3}\right)_{3}>\mathrm{AgNO}_{3}>\mathrm{KNO}_{3}> \\
\mathrm{NaNO}_{3}>\mathrm{NH}_{4} \mathrm{NO}_{3}>\mathrm{Pb}\left(\mathrm{NO}_{3}\right)_{2}>\mathrm{Ba}\left(\mathrm{NO}_{3}\right)_{2} \text {. }\end{array}$ \\
\hline
\end{tabular}

The nitration methods of nitrogen-rich heterocyclic EMs of azoles (imidazole, pyrazole, triazole, tetrazole, oxadiazole) and azines (pyrazine, pyridazine, triazine, tetrazine) were reviewed. Most of the above nitro-containing nitrogen-rich heterocyclic EMs have higher density, outstanding enthalpy of formation, and excellent oxygen balance. Generally speaking, nitrogen-rich compounds with high density and enthalpy of formation always have high detonation performance. Although there are many nitration methods of nitrogenrich heterocyclic EMs reported in the literature, there are still some problems that need to be explored and studied. The authors believe that the following aspects of research should be noted in the future:

1. Nitramino-containing nitrogen-rich EMs have higher sensitivity, and these materials can be used as primary explosives. From the viewpoint of chemical reactivity, the nitro group attached to the heterocyclic carbon adjacent to the nitrogen on the heterocyclic ring is unstable to hydrolysis. The existence of adjacent $\mathrm{C}$-amino groups will improve the stability of the ring, and the lone pair of electrons on the amino nitrogen provides electrons to the ring system, thus, the sensitivity of the nitro group to hydrolysis can 
be significantly reduced. In addition, the presence of amino and nitro groups will boost the formation enthalpy, oxygen balance, density, and stability of the compound, thereby enhancing the detonation and safety of the compound $[6,20,55]$. Therefore, when designing the molecular structure of EMs, it should be designed as far as possible with compounds where nitro and amino groups cross, such as 3,6-diamino4,6-dinitropyridazine-1-oxide (Scheme 36) and 2,6-diamino-3,5-dinitropyrazine-1oxide (LLM-105) (Scheme 37);

2. Applying organic synthesis technologies, such as ultrasound and microwave, to the nitration process of nitrogen-rich heterocyclic energetic compounds to shorten the time and improve the overall yield is imperative;

3. In view of the traditional methods for synthesizing nitro-containing heterocyclic energetic compounds, including a series of problems brought about by the application of oleum sulfuric acid and fuming nitric acid, it is necessary to continue research so as to discover new nitrification methods to adapt to new needs, especially paying more attention to the development of some low-toxic, cheap, efficient, and environmentally friendly nitrification strategies to adapt to the implementation of sustainable development strategies and the practical application of green chemistry.

Author Contributions: Conceptualization, X.W. and Y.L.; investigation, W.Z. and F.S.; writingoriginal draft preparation, Y.L. and W.Z.; writing-review, X.W. and Y.L.; editing, F.S.; Y.L. and W.Z. contributed equally to this work. All authors have read and agreed to the published version of the manuscript.

Funding: This research received no external funding.

Institutional Review Board Statement: Not applicable.

Informed Consent Statement: Not applicable.

Data Availability Statement: Not applicable.

Conflicts of Interest: The authors declare no conflict of interest.

\section{References}

1. Zhang, C.; Chen, X.; Bai, Y.; Guo, Z.Q.; Song, J.R.; Ma, H.X. 6-((2H-tetrazol-5-yl)-amino)-1,2,4,5-tetrazin-3(2H)-one: High-nitrogen insensitive energetic compound stabilized by $\pi$-stacking and hydrogen-bonding interaction. Chin. J. Energetic Mater. 2020, 28, 182-189.

2. Peng, F.; Yao, Y.; Liu, H.; Ma, Y. Crystalline $\mathrm{LiN}_{5}$ predicted from first-principles as a possible high-energy material. J. Phys. Chem. Lett. 2015, 6, 2363-2366. [CrossRef] [PubMed]

3. Xu, Y.; Lin, Q.; Wang, P.; Lu, M. Syntheses, crystal structures and properties of a series of 3D metal-inorganic frameworks containing pentazolate anion. Chem. Asian J. 2018, 13, 2786-2790. [CrossRef] [PubMed]

4. Zhang, C.; Sun, C.; Hu, B.; Yu, C.; Lu, M. Synthesis and characterization of the pentazolate anion cyclo- $\mathrm{N}_{5}-\mathrm{in}\left(\mathrm{N}_{5}\right) 6\left(\mathrm{H}_{3} \mathrm{O}\right)_{3}\left(\mathrm{NH}_{4}\right)_{4} \mathrm{Cl}$. Science 2017, 355, 374-376. [CrossRef]

5. Chavez, D.E.; Parrish, D.A.; Mitchell, L. Energetic Trinitro- and Fluorodinitroethyl Ethers of 1,2,4,5-Tetrazines. Angew. Chem. Int. Ed. 2016, 55, 8666-8669. [CrossRef]

6. Wang, Y.; Liu, Y.J.; Song, S.W.; Yang, Z.J.; Qi, X.J.; Wang, K.C.; Liu, Y.; Zhang, Q.H.; Tian, Y. Accelerating the discovery of insensitive high-energy-density materials by a materials genome approach. Nat. Commun. 2018, 9, 2444. [CrossRef]

7. Thomas, M.K.; Carles, M.S. Nitrogen-Rich Tetrazolium Azotetrazolate Salts: A New Family of Insensitive Energetic Materials. Chem. Mater. 2008, 20, 1750-1763.

8. Wang, Y.; Ye, J.; Yang, N.; Ma, H.X.; Zhang, Y.Z.; Guo, Z.Q. Strong intermolecular interaction induced methylene-bridged asymmetric heterocyclic explosives. CrystEngComm. 2021, 23, 7635-7642. [CrossRef]

9. Fu, W.; Zhao, B.; Zhang, M.; Li, C.; Gao, H.; Zhang, J.; Zhou, Z. 3,4-Dinitro-1-(1H-tetrazol-5-yl)-1H-pyrazol-5-amine (HANTP) and its salts: Primary and secondary explosives. J. Mater. Chem. A 2017, 5, 5044-5054. [CrossRef]

10. Huang, S.; Tian, J.; Qi, X.; Wang, K.; Zhan, Q. Synthesis of gem-dinitromethylated and fluorodinitromethylated derivatives of 5,5'-dinitro-bis-1,2,4-triazole as promising high-energy-density materials. Chem. Eur. J. 2017, 23, 12787-12794. [CrossRef]

11. Xu, Y.; Wang, Q.; Shen, C.; Lin, Q.; Wang, P.; Lu, M. A series of energetic metal pen-tazolate hydrates. Nature 2017, 549, 78-81. [CrossRef] [PubMed]

12. Yin, P.; Zhang, Q.; Shreeve, J.M. Dancing with energetic nitro-gen atoms: Versatile N-functionalization strategies for N-heterocyclic frameworks in high energy density materials. Acc. Chem. Res. 2016, 49, 14-16. [CrossRef] [PubMed] 
13. Dippold, A.A.; Klapötke, T.M. Synthesis and Characterization of 5-(1,2,4-Triazol-3-yl)tetrazoles with Various Energetic Functionalities. Chem. An. Asian J. 2013, 8, 1463-1471. [CrossRef]

14. Klapötke, T.M.; Preimesser, A.; Stierstorfer, J. Energetic derivatives of 4,4',5,5'-tetranitro-2,2'-bisimidazole(TNBI). Z. Anorg. Allg. Chem. 2012, 638, 1278-1286. [CrossRef]

15. Li, Y.N.; Shu, Y.J.; Zhang, S.Y.; Wang, B.Z.; Zhai, L.J. Synthesis and Thermal Properties of 4,4' $15,5^{\prime}$-Tetranitro-2,2'-biimidazole and Its Energetic Ion Salts. Chin. J. Energ. Mater. 2017, 25, 298-303.

16. Klapötke, T.M.; Preimesser, A.; Stierstorfer, J. Energetic Derivatives of 2-Nitrimino-5,6-dinitrobenzimidazole. Propell. Explos. Pyrot. 2015, 40, 60-66. [CrossRef]

17. Yin, P.; He, C.; Shreeve, J.M. Fully C/N-Polynitro-Functionalized 2,2'-Biimidazole Derivatives as Nitrogen- and Oxygen-Rich Energetic Salts. Chem. Eur. J. 2016, 22, 2108-2113. [CrossRef]

18. Chand, D.; He, C.; Mitchell, L.A.; Parrish, D.A.; Shreeve, J.M. Electrophilic iodination: A gateway to high iodine compounds and energetic materials. Dalton Trans. 2016, 45, 13827-13833. [CrossRef]

19. Ravi, P.; Tewari, S.P. Facile and environmentally friendly synthesis of nitropyrazoles using montmorillonite K-10 impregnated with bismuth nitrate. Catal. Commun. 2012, 19, 37-41. [CrossRef]

20. Fischer, D.; Gottfried, J.L.; Klapötke, T.M.; Karaghiosoff, K.; Stierstorfer, J.; Witkowski, T.G. Synthesis and Investigation of Advanced Energetic Materials Based on Bispyrazolylmethanes. Angew. Chem. Int. Ed. 2016, 55, 16132-16135. [CrossRef]

21. Wang, G.L.; Lu, T.; Fan, G.J.; Li, C.; Yin, H. The Chemistry and Properties of Energetic Materials Bearing [1,2,4]Triazolo[4,3b][1,2,4,5]tetrazine Fused Rings. Chem. Asian J. 2018, 13, 3718-3722. [CrossRef]

22. Yin, P.; Zhang, J.H.; Parrish, D.A.; Shreeve, J.M. Energetic $N, N^{\prime}$-Ethylene-Bridged Bis(nitropyrazoles): Diversified Functionalities and Properties. Chem. Eur. J. 2014, 20, 16529-16536. [CrossRef] [PubMed]

23. Zhang, Y.Q.; Parrish, D.A.; Shreeve, J.M. 4-Nitramino-3,5-dinitropyrazole Based Energetic Salts. Chem. Eur. J. 2012, 18, 987-994. [CrossRef] [PubMed]

24. He, C.L.; Zhang, J.H.; Parrish, D.A.; Shreeve, J.M. 4-Chloro-3,5-dinitropyrazole: A precursor for promising insensitive energetic compounds. Mater. Chem. A 2013, 1, 2863-2868. [CrossRef]

25. Tang, Y.X.; Kumar, D.; Shreeve, J.M. Balancing Excellent Performance and High Thermal Stability in a Dinitropyrazole Fused 1,2,3,4-Tetrazine. J. Am. Chem. Soc. 2017, 139, 13684-13687. [CrossRef] [PubMed]

26. Kumar, D.; Tang, Y.X.; He, C.L.; Imler, G.H.; Parrish, D.; Shreeve, J.M. Multipurpose Energetic Materials by Shuffling Nitro Groups on a 3,3'-Bipyrazole Moiety. Chem. Eur. J. 2018, 24, 17220-17224. [CrossRef]

27. Yin, P.; Zhang, J.H.; Mitchell, L.A.; Parrish, D.A.; Shreeve, J.M. 3,6-Dinitropyrazolo[4,3-c]pyrazole-Based Multipurpose Energetic Materials through Versatile N-Functionalization Strategies. Angew. Chem. Int. Ed. 2016, 55, 12895-12897. [CrossRef]

28. Ma, H.X.; Xiao, H.M.; Song, J.R.; Ju, X.H.; Zhu, W.; Yu, K.B. Molecular structure of 4-amino-1,2,4- triazol-5-one and a densityfunctional theoretical investigation of its dimers and crystal band structure. Chem. Phys. 2008, 344, 79-89. [CrossRef]

29. Chang, P.; Zhou, C.; Wang, B.Z.; Huang, X.P.; Zhu, Y. Safety Analysis of Two NTO Synthesis Processes. J. Chem. Eng. Chin. Univ. 2018, 32, 1223-1227. (In Chinese)

30. Huang, X.P.; Chang, P.; Wang, B.Z.; Li, P.R.; Wang, M.C.; Fan, X.Z.; Feng, H.L. Recycling use of waste acids in preparation of 3-nitro-1,2,4-triazol-5-one (NTO). Chin. J. Energ. Mater. 2013, 21, 363-366. (In Chinese)

31. Aizikovich, A.; Shlomovich, A.; Cohen, A. The nitration pattern of energetic 3,6-diamino-1,2,4,5-tetrazine derivatives containing azole functional groups. Dalton Trans. 2015, 44, 13939-13946. [CrossRef] [PubMed]

32. Astachov, A.M.; Revenko, V.A.; Buka, E.S. Comparative characteristics of two isomeric explosives: 4-nitro-5-nitrimino-1H-1,2,4triazole and 3-nirro-5-nitrimino-1,4H-1,2,4-triazole. In Proceedings of the Seminar on New Trends in Research of Energetic Materials, Pardubice, Czech Republic, 20 April 2004.

33. Dippold, A.A.; Klapötke, T.M. Nitrogen-Rich Bis-1,2,4-triazoles-A Comparative Study of Structural and Energetic Properties. Chem. Eur. J. 2012, 18, 16742-16753. [CrossRef] [PubMed]

34. Yin, P.; Shreeve, J.M. From N-Nitro to N-Nitroamino: Preparation of High-Performance Energetic Materials by Introducing Nitrogen-Containing Ions. Angew. Chem. Int. Ed. 2015, 54, 14513-14517. [CrossRef] [PubMed]

35. Klapötke, T.M.; Leroux, M.; Schmid, P.C.; Stierstorfer, J. Energetic Materials Based on 5,5' -Diamino-4,4'-dinitramino-3,3'-bi-1,2,4triazole. Chem. Asian J. 2016, 11, 844-851. [CrossRef]

36. Zhang, Y.Q.; Parrish, D.A.; Shreeve, J.M. Derivatives of 5-nitro-1,2,3-2H-triazole-high performance energetic materials. J. Mater. Chem. A 2013, 1, 585-593. [CrossRef]

37. Thottempudi, V.; Forohor, F.; Parrish, D.A.; Shreeve, J.M. Tris(triazolo)benzene and Its Derivatives: High-Density Energetic Materials. Angew. Chem. Int. Ed. 2012, 51, 9881-9885. [CrossRef]

38. Stierstorfer, J.; Tarantik, K.R.; Klapötke, T.M. New Energetic Materials: Functionalized 1-Ethyl-5-aminotetrazoles and 1-Ethyl-5nitriminotetrazoles. Chem. Eur. J. 2009, 15, 5775-5792. [CrossRef]

39. Fischer, D.; Klapötke, T.M.; Stierstorfer, J. 1,5-Di(nitramino)tetrazole: High Sensitivity and Superior Explosive Performance. Angew. Chem. Int. Ed. 2015, 54, 10299-10302. [CrossRef]

40. Kumar, D.; Imler, G.H.; Parrish, D.A.; Shreeve, J.M. Aminoacetonitrile as precursor for nitrogen rich stable and insensitive asymmetric $N$-methylene-C linked tetrazole-based energetic compounds. Mater. Chem. A 2017, 5, 16767-16775. [CrossRef]

41. Klapötke, T.M.; Martin, F.A.; Stierstorfer, J. N-Bound Primary Nitramines Based on 1,5-Diaminotetrazole. Chem. Eur. J. 2012, 18, 1487-1501. [CrossRef] 
42. Fischer, D.; Klapötke, T.M.; Stierstorfer, J.; Szimhardt, N. 1,1'-Nitramino-5,5'-bitetrazoles. Chem. Eur. J. 2016, 22, 4966-4970. [CrossRef] [PubMed]

43. Tang, Y.X.; Gao, H.X.; Mitchell, L.A.; Parrish, D.A.; Shreeve, J.M. Syntheses and Promising Properties of Dense Energetic 5,5'-Dinitramino-3,3'-azo-1,2,4-oxadiazole and Its Salts. Angew. Chem. Int. Ed. 2016, 55, 3200-3203. [CrossRef] [PubMed]

44. Tang, Y.X.; Gao, H.X.; Mitchell, L.A.; Parrish, D.A.; Shreeve, J.M. Enhancing Energetic Properties and Sensitivity by Incorporating Amino and Nitramino Groups into a 1,2,4-Oxadiazole Building Block. Angew. Chem. Int. Ed. 2016, 55, 1147-1150. [CrossRef] [PubMed]

45. Hermann, T.S.; Karaghiosoff, K.; Klapötke, T.M.; Stierstorfer, J. Synthesis and Characterization of 2,2'-Dinitramino-5,5'-bi(1oxa-3,4-diazole) and Derivatives as Economic and Highly Dense Energetic Materials. Chem. Eur. J. 2017, 23, 12087-12091. [CrossRef]

46. Sheremetev, A.B.; Aleksandrova, N.S. Reactions of 3-amino-4-methylfurazan with nitrating agents. Russ. Chem. Bull. Int. Ed. 2005, 54, 1665-1669. [CrossRef]

47. Fischer, D.; Klapötke, T.M.; Reymann, M.; Stierstorfer, J. Dense Energetic Nitraminofurazanes. Chem. Eur. J. 2014, $20,6401-6411$. [CrossRef]

48. Zhang, J.H.; Dharavath, S.; Mitchell, L.A.; Parrish, D.A.; Shreeve, J.M. Bridged bisnitramide-substituted furazan-based energetic materials. J. Mater. Chem. A 2016, 4, 16961-16967. [CrossRef]

49. Klapötke, T.M.; Schmid, P.C.; Stierstorfer, J. Crystal Structures of Furazanes. Crystals 2015, 5, 418-432. [CrossRef]

50. Gospodinov, I.; Klapötke, T.M.; Stierstorfer, J. Energetic Functionalization of the Pyridazine Scaffold: Synthesis and Characterization of 3,5-Diamino-4,6- dinitropyridazine-1-Oxide. Eur. J. Org. Chem. 2018, 8, 1004-1010. [CrossRef]

51. Zhou, X.L.; Liu, Z.L.; Cheng, J.; Zhao, X. Study on nitration reaction of 2,6-diacetamidopyrazine-1-oxide. Explos. Mater. 2014, 43, 16-21. (In Chinese)

52. Liu, J.D.; Shen, C.; Wang, P.C.; Lu, M. Synthesis and Properties of 2,6-Bis(picryIamino)-3,5-dinitroPyrazine. Chin. J. Energetic Mater. 2017, 25, 486-492.

53. Huang, Y.G.; Zhang, Y.Q.; Shreeve, J.M. Nitrogen-Rich Salts Based on Energetic Nitroaminodiazido [1,3,5]triazine and Guanazine. Chem. Eur. J. 2011, 17, 1538-1546. [CrossRef] [PubMed]

54. Zhang, T.H.; Du, J.; Li, Z.M.; Lin, X.; Wang, L.; Yang, L.; Zhang, T.L. Alkali metal salts of 3,6-dinitramino-1,2,4,5-tetrazine: Promising nitrogen-rich energetic materials. Cryst. Eng. Comm. 2019, 21, 765-772. [CrossRef]

55. Tang, Y.X.; He, C.L.; Imler, G.H.; Parrish, D.A.; Shreeve, J.M. A C-C bonded 5,6-fused bicyclic energetic molecule: Exploring an advanced energetic compound with improved performance. Chem. Commun. 2018, 54, 10566-10569. [CrossRef] 